\title{
Lilian Corrêa
}

\section{Tratamento do prolapso da cúpula vaginal pela técnica da sacropexia infracoccígea}

Dissertação apresentada à Faculdade de Medicina da Universidade de São Paulo para obtenção do Título de Mestre em Ciências

Área de Concentração: Obstetrícia e Ginecologia Orientador: Prof. Dr. Ricardo Muniz Ribeiro

São Paulo

2009 
Dados Internacionais de Catalogação na Publicação (CIP)

Preparada pela Biblioteca da

Faculdade de Medicina da Universidade de São Paulo

Creprodução autorizada pelo autor

\section{Corrêa, Lilian}

Tratamento do prolapso da cúpula vaginal pela técnica da sacropexia infracoccígea / Lilian Corrêa. -- São Paulo, 2009.

Dissertação(mestrado)--Faculdade de Medicina da Universidade de São Paulo. Departamento de Obstetrícia e Ginecologia.

Área de concentração: Obstetrícia e Ginecologia.

Orientador: Ricardo Muniz Ribeiro.

Descritores: 1.Vagina/cirurgia 2.Prolapso uterino 3.Procedimentos cirúrgicos urogenitais 4.Telas cirúrgicas 5.Polipropilenos/uso terapêutico 6.Qualidade de vida

USP/FM/SBD-308/09 
A DEUS,

Sem o qual minha existência não teria sentido. 
Este trabalho é dedicado:

A meus queridos pais,

pelo amor, carinho, exemplo de luta e honestidade, por tudo o que me ensinaram ao longo da minha vida.

Ao amor da minha vida, Néu,

pelo amor, carinho, paciência inesgotável, incentivo em todas as horas, companheiro constante, mesmo nas longas madrugadas de trabalho.

As minhas irmãs,

Eliete e Franceli, pelo apoio e carinho nas horas difíceis.

Ao meu querido Igor, pelas alegrias que me proporcionou. 


\section{Agradecimentos}

Ao Prof. Dr. Edmund Chada Baracat, pelo exemplo de dedicação a ser seguido e paciência das longas horas de correção deste trabalho.

Ao Prof. Dr. Ricardo Muniz Ribeiro, pela oportunidade oferecida, pela paciência nestes anos de trabalho, pelas orientações e preocupação em todas as horas e principal responsável pela realização deste trabalho.

Ao Dr. Jorge Milhem Haddad, pelo companheirismo, incentivo constante e força nas horas mais complicadas; meu grande amigo.

A Dra. Aparecida Maria Pacetta, pelos ensinamentos, orientações e apoio.

A Dra. Sylvia Helena Colletti, pelas longas horas de cirurgia dedicadas no auxilio deste trabalho; pela força e ajuda.

Ao Prof. Dr. José Aristodemo Pinotti, pela oportunidade e apoio iniciais, indispensáveis na execução deste tratalho.

As Prof. Dras. Ceci Mendes Carvalho e Sylvia Yamashita, pela amizade e longas horas de ensinamento.

Ao Dr. Miguel Bartolomé Vera, meu mestre em cirurgia, pelos ensinamentos, pelo carinho, meu amigo.

Ao Dr. Homero G. Campos Guidi, pelas discussões e apoio.

A Dra. Simone dos Reis Brandão da Silveira, pela amizade e apoio nas fases iniciais deste trabalho. 
A Dra. Patrícia de Rossi, pela amizade e apoio, maior incentivadora por eu ter seguido o campo da Uroginecologia.

A Dra. Luciana Pistelli, pela amizade, pela ajuda nas fases finais deste trabalho e pela força e paciência quando carregou meus pôsteres para Itália.

A Dra. Lais Yassuda, pela amizade e companheirismo nas horas cirúrgicas.

Aos Drs. Miguel, Jeane, Ana Cristina, pelas horas de apoio no ambulatório.

Aos meus amigos Paulo, Alice, Eliete, Beatriz, pelo carinho e amizade.

A Marilu, pelas correções ortográficas e da língua inglesa.

Ao Marcos Maeda, pela elaboração da análise estatística.

As pacientes, sem as quais este trabalho não existiria.

A todos aqueles que, direta ou indiretamente, colaboraram para a realização desta tese, minha gratidão. 


\section{SUMÁRIO}

Resumo

Summary

1 Introdução

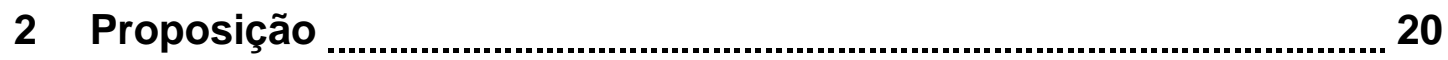

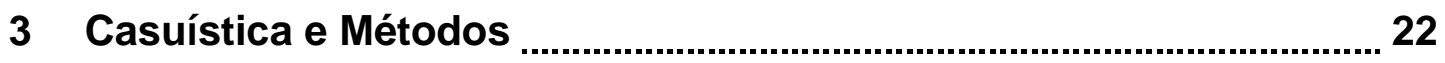

3.1 Casuística .................................................................................. 23

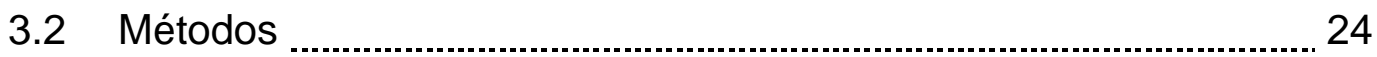

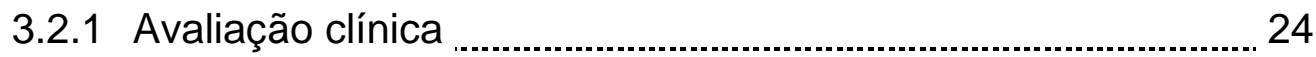

3.2.1.1 Exame Ginecológico .................................................. 25

3.2.1.2 Questionário de Qualidade de Vida ................................ 25

3.2.2 Técnica Cirúrgica da Sacropexia Infracoccígea ...................... 27

3.2.3 Análise Estatística ............................................................... 28

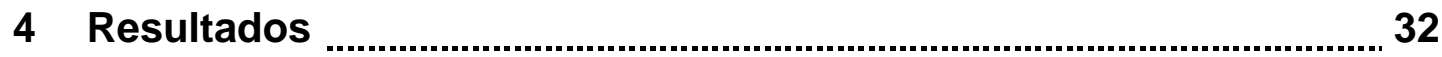

4.1Avaliação clínica do prolapso ............................................................. 33

4.1.1 Exame ginecológico: avaliação da cúpula vaginal ................... 34

4.1.2 Questionário de Qualidade de Vida em Prolapso .................... 36

4.1.2.1 Somatória de todos os domínios .................................. 36

4.1.2.2 Evolução de cada domínio do questionário ................... 37

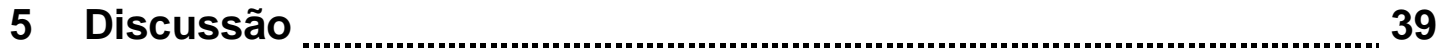

5.1 Avaliação do prolapso da parede vaginal anterior ......................... 42

5.2 Avaliação do prolapso da parede vaginal posterior ........................ 44

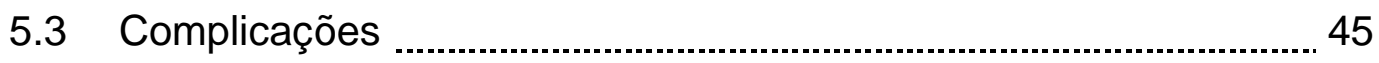


5.3.1 Complicações peri-operatórias 45

5.3.2 Incontinência Urinária de Esforço 46

5.3.3 Extrusão da faixa/rejeição 46

5.3.4 Dor relacionada ao procedimento cirúrgico 47

5.3.5 Sexualidade 47

5.3.6 Qualidade de Vida 48

6 Conclusão 50

7 Anexos 52

7.1 Anexo A: Termo de Consentimento Livre e Esclarecido 53

7.2 Anexo B: Questionário de Qualidade de Vida em Prolapso 57

7.3 Anexo C: Evolução do Ponto Ba na casuística estudada 65

7.4 Anexo D: Evolução do Ponto Bp na casuística estudada 67

7.5 Anexo E: Evolução do Ponto C na casuística estudada 69

8 Referências 71 


\section{RESUMO}

Correa LC. Tratamento do prolapso da cúpula vaginal pela Técnica da Sacropexia infracoccígea [dissertação]. São Paulo: Faculdade de Medicina, Universidade de São Paulo. 2009. 78p.

O prolapso da cúpula vaginal é uma patologia rara, que há mais de 100 anos sua fisiopatologia e tratamento têm sido alvo de discussão, devido ao grau de dificuldade de um tratamento com preservação da anatomia. A técnica considerada como padrão-ouro para esta correção é a promontofixação abdominal, porém a alta morbidade associada à laparotomia é um fator de restrição ao uso da técnica. Neste aspecto, as técnicas de abordagens vaginais oferecem vantagem de menor morbidade e menor tempo cirúrgico quando comparadas às técnicas abdominais. Este trabalho teve por objetivo avaliar a Técnica da Sacropexia Infracoccígea na fixação da cúpula vaginal. Foram estudadas 36 mulheres com prolapso da cúpula vaginal no período de março de 2004 à fevereiro de 2008 as quais foram submetidas ao tratamento cirúrgico para correção do prolapso segundo a Técnica da Sacropexia Infracoccígea. As mulheres foram estadiadas quanto ao grau do prolapso segundo a Padronização dos Prolapsos Genitais da ICS - POPq antes e após o procedimento e foram submetidas a avaliação da qualidade de vida através da aplicação do Questionário de Qualidade de Vida em Prolapso, nos mesmos períodos de avaliação do exame ginecológico. Para avaliar a cúpula vaginal foi utilizado o Ponto $\mathrm{C}$ do POPq e submetido a tratamento estatístico. As mulheres foram acompanhadas por um tempo médio de 30,9 meses (10 a 55 meses). O Ponto $C$ avaliado antes e após o procedimento variou de média de +6 (antes do procedimento) para média de -6,5 (após 24 meses da correção). A variação do Ponto C foi estatisticamente significante. Houve somente uma recidiva do prolapso após 24 meses de avaliação. Quanto ao Questionário de Qualidade de vida houve redução significativa da pontuação pós-operatória, mostrando melhora importante na qualidade de vida das mulheres estudadas $(p<0,05)$. Em uma média de 30,9 meses de estudo a técnica foi eficaz na redução do prolapso da cúpula vaginal e na melhora da qualidade de vida das mulheres estudadas.

Descritores: 1.Vagina/cirurgia 2.Prolapso uterino 3.Procedimentos cirúrgicos urogenitais 4.Telas cirúrgicas 5.Polipropilenos/uso terapêutico 6.Qualidade de vida 


\section{SUMMARY}

Correa LC. Treatment of vaginal vault prolapse by infracoccigeal sacropexy technique [dissertation]. São Paulo: "Faculdade de Medicina, Universidade de São Paulo". 2009. 78p.

The vaginal vault prolapse isn't a common pathology that there are at least one hundred years it's physiopathology and treatment have been discussed. It's occurs mainly by the difficulty to find an anatomic preservation treatment. The most accept technique is the abdominal colposacropexy and it's considered the gold standard for some authors, although the high morbidity associated with it is a restriction factor. On the other hand, the vaginal techniques take less morbidity and less surgical time to perform the procedure regards abdominal techniques. The objective of this work was to evaluate long-term results and long-term patients satisfaction of infracoccigeal sacropexy technique performed for massive vaginal vault prolapse. A prospective analysis was performed of 36 women who underwent vaginal vault prolapse correction by the infracoccigeal sacropexy technique during the period of march, 2004 to February, 2008. The gynecological exam was performed by the Pelvic Organ Prolapse Standardization (POP-q) and a validated questionnaire (Prolapse Quality of Life Questionnaire) was used to evaluate patients' satisfaction before and after surgery, at the same evaluation periods. To evaluate the vaginal vault prolapse, the Point $\mathrm{C}$ of POPq was taken before and after surgery and an appropriate statistical analysis was performed. The women was followed by a mean time of 30,9 months ( 10 to 55 months). The point $C$ variation media was +6 before the procedure to $-6,5$ after the procedure (after 24 months after surgery). It was statistically significant $(p<0,05)$. There was only one vaginal vault prolapse recurrence after 24 months of evaluation. The quality of life questionnaire showed patients' satisfaction was statistically improved after the procedure $(p<0,05)$. Taking a mean time of 30,9 months the technique was efficient to reduce the vaginal vault prolapse and to improve the quality of life in the group of study.

Descriptors: 1.Vagina/surgery 2.Uterine prolapse 3.Urogenital surgical procedures 4.Surgical mesh 5.Polypropylenes/therapeutic use 6.Quality of life 
1. Introdução 
O prolapso da cúpula vaginal é uma complicação rara. Há poucos dados na literatura relacionados à sua incidência. Estudo coorte realizado em 1997 mostrou ser a incidência de qualquer tipo de prolapso vaginal após histerectomia de 3,6 por 1000 mulheres/ano, sem nenhuma menção à do prolapso da cúpula vaginal isolado. ${ }^{1}$

Para tentar estimar a sua incidência, Marchionni em 1999, estudando uma coorte de 2670 mulheres histerectomizadas, encontrou 4,4\% de prolapso de cúpula, porém, somente $0,2 \%$ foram operadas pela queixa clínica do prolapso; as demais eram assintomáticas. ${ }^{2}$

Corroborando com estes achados, Dallenbach, em 2008, avaliando retrospectivamente os casos de prolapso de cúpula vaginal submetidos à correção cirúrgica, e examinando uma coorte de 6214 histerectomias realizadas no período de 1982 a 2002, encontrou incidência de cirurgias para correção do prolapso da cúpula em 0,36 por 1000 mulheres/ano. Quando a histerectomia prévia à correção desse tipo de prolapso havia sido realizada por prolapso genital, a incidência aumentava para 1,1 por 1000 mulheres/ano, contra 0,2 por 1000 mulheres/ano quando a histerectomia havia sido realizada por outros motivos que não o prolapso genital. ${ }^{3,4}$

Entre os fatores de risco para a ocorrência dessa afecção, a atividade sexual, a multiparidade, a incontinência urinária de esforço e a presença de qualquer prolapso vaginal independente de qual o compartimento afetado, foram associadas ao aumento de incidência. O estado menopausal, quando associado ao uso de terapia hormonal, 
mostrou tendência ao aumento do risco, porém não significativo. A obesidade não se relacionou ao risco. ${ }^{4}$

Embora alguns autores não tenham encontrado diferenças significativas na incidência, é incomum na raça negra, pouco comum na asiática e mais freqüente na raça branca. $^{5}$ Além disso, $2 \%$ de jovens nulíparas podem ter prolapso dos órgãos genitais devido à fraqueza das estruturas de suporte conectivo das estruturas pélvicas. ${ }^{6,7}$

Estes dados sugerem que o prolapso ocorre por provável fraqueza dos tecidos pélvicos. Com efeito, os estudos ao longo do século $X X$ têm mostrado evidências deste fato. ${ }^{8}$

Já no início do século XX (1907/1908), dois cirurgiões britânicos, Fothergill e Paramore, discutindo a provável etiologia do prolapso, afirmavam que não só as estruturas ligamentares uterinas eram importantes na sustentação, baseados no princípio da reconstrução dos suportes fasciais do útero, mas também a musculatura do assoalho pélvico e a fascia visceral eram igualmente importantes. ${ }^{9,10}$

De Lancey, em 1994, após 74 dissecções em cadáveres, demonstrou a relevância do tecido conectivo na sustentação dos órgãos pélvicos, além da sustentação muscular. Descreveu três níveis de suporte vaginal:

a) Nível I: terço cranial da vagina, sustentado nas paredes pélvicas por fibras verticais dos ligamentos útero-sacrais e cardinais; 
b) Nível II: terço medial da vagina, onde a sustentação ocorre através da fixação lateral dos ligamentos cardinais ao arco tendínio e à fáscia da musculatura elevadora do ânus;

c) Nível III: terço distal vaginal, que se funde à membrana perineal, à musculatura elevadora do ânus e corpo perineal;

O autor concluiu que a sustentação do nível I, representado pelos ligamentos útero-sacrais e cardinal era o fator determinante para a fixação da cúpula vaginal e, portanto, para a prevenção do seu prolapso, uma vez que quando íntegro impedia o prolapso da cúpula vaginal mesmo em pacientes com procidência das paredes vaginais anterior e posterior. ${ }^{11}$

Em concordância com De Lancey, Petros, em 2001, descreveu a dinâmica envolvida no suporte da vagina. Utilizando ultrassom, estudou a dinâmica da placa elevadora do ânus e da vagina durante o esforço. Demonstrou que durante o esforço, a base da bexiga, a vagina proximal e o reto eram desviados na direção posterior e sofriam rotação para a direção inferior, enquanto a parte distal da vagina era estendida no sentido anterior. Ao repouso, tomando-se como base uma linha horizontal passando pela borda inferior do púbis, o ângulo vaginal com relação a esta linha base era inferior a 45 graus e, ao esforço, contraído a 0 grau, comprimindo significativamente a vagina e o nível II contra o reto, desfavorecendo a herniação dos órgãos pélvicos através da vagina. ${ }^{12}$

Ao contrário, em grandes multíparas, este ângulo era maior que 45 graus ao repouso, e não havia a compressão vaginal e do nível II contra o 
reto durante o esforço. Isto ocorria apesar da integridade da placa elevadora do ânus, com subseqüente prolapso significante da vagina e do útero. Com base nesses dados, a lesão muscular por si só não é capaz de explicar o aparecimento do prolapso, sugerindo que outros fatores, como flacidez do tecido conectivo, devem colaborar na gênese do prolapso útero-vaginal.

Além disso, nas biópsias realizadas nos tecidos conectivos de sustentação da vagina, do corpo perineal e da fascia endopélvica, demonstrou-se a presença de nervos e de musculatura lisa nestas estruturas, que provavelmente encontram-se ativos durante o esforço. 0 estiramento exagerado desta musculatura pode lesar de modo irreversivel sua habilidade de contração.

Com relação à avaliação clínica, as queixas mais freqüentes são: sensação de peso na vagina ou vulva; aparecimento de abaulamento que se exterioriza pela rima vulvar; tumor que se protrui entre as pernas, dificuldade de evacuação ou esvaziamento vesical associado ou não à necessidade de redução do abaulamento. A restrição da atividade social, com confinamento na residência por incômodo relacionado ao prolapso, dificuldade de sentar ou necessidade do uso de cintas para compressão do prolapso também são queixas comuns, bem como a redução da atividade sexual por vergonha do parceiro.

Para avaliação do prolapso durante o exame ginecológico, a International Continence Society (ICS), publicou, em 1996, uma padronização da terminologia dos prolapsos dos órgãos pélvicos femininos 
de modo a uniformizar as definições relacionadas ao prolapso genital e apresentar uma classificação quantitativa dos mesmos. O objetivo era permitir a reprodutibilidade da avaliação e do significado clínico dos diferentes graus de prolapso (Pelvic Organ Prolapse Quantification System POP-Q). ${ }^{13}$ Desde então, a avaliação clínica dos prolapsos genitais segue essa padronização.

A descrição clínica da anatomia do assoalho pélvico é determinada durante o exame físico da genitália externa e da vagina, sendo necessário o máximo de protrusão vaginal para que o prolapso seja avaliado adequadamente. A classificação baseia-se em um ponto de referência fixo e em seis pontos definidos localizados nas paredes vaginais tomando-se como base essa referência. O ponto de referência é o hímen, que é considerado o plano 0. Os pontos definidos nas paredes vaginais são medidos em centímetros de distância do hímen, sendo que os pontos proximais ou acima do hímen são classificados como números negativos e os pontos abaixo ou distais como números positivos (Figura 1). 


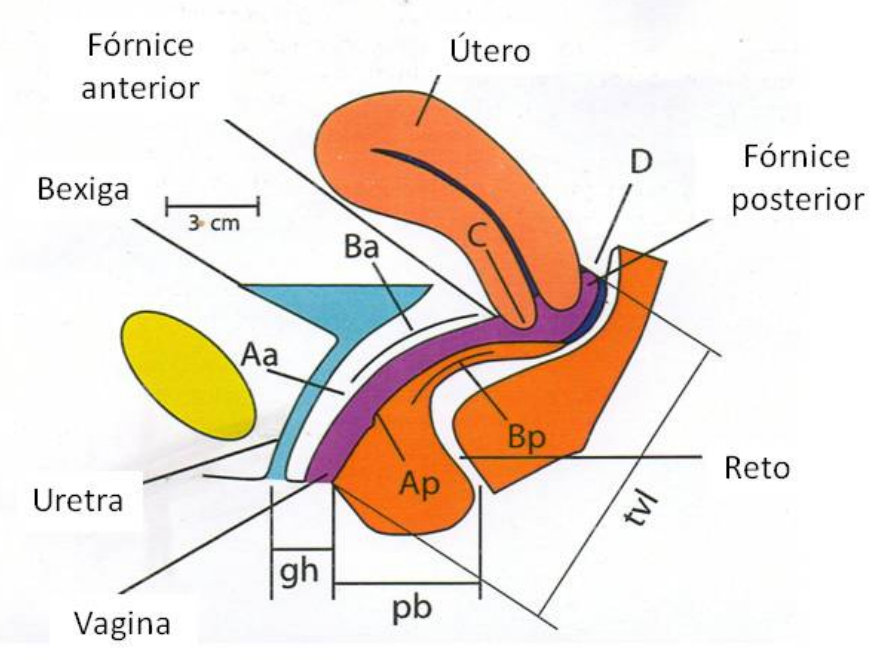

Figura 1 - Esquema da Classificação dos Prolapsos Genitais da ICS (Pelvic Organ Prolapse Quantification System - POP-Q)

Os pontos definidos nas paredes vaginais com relação ao hímen são: dois na parede vaginal anterior, dois no ápice vaginal e dois na parede vaginal posterior:

a) Ponto Aa: ponto localizado na parede vaginal anterior, $3 \mathrm{~cm}$ acima do meato uretral externo; a sua variação máxima é de -3 à +3;

b) Ponto Ba: ponto localizado na extremidade mais distal da parede vaginal anterior (durante o prolapso máximo) medido entre o ponto 
Aa e o fórnice vaginal anterior; por definição, na ausência de prolapso ele está em -3;

c) Ponto C: ponto que representa a porção mais distal da cérvice uterina ou cúpula vaginal;

d) Ponto D: ponto localizado no fórnice vaginal posterior (fundode-saco de Douglas), ao nível da união do ligamento útero-sacro à cérvice. É excluído na ausência do colo uterino;

e) Ponto Ap: ponto localizado 3cm proximal ao hímen na parede vaginal posterior;

f) Ponto Bp: ponto que representa o local da maior protrusão da parede vaginal posterior entre o Ponto Ap e o fórnice vaginal posterior ou cúpula vaginal. Por definição, na ausência de prolapso ele está no -3;

g) GH ("genital hiatus"): medido entre a metade do hiato uretral externo até o hímen posterior;

h) PB ("perineal body"): medido do $\mathrm{GH}$ até o ponto médio do orifício anal;

i) TVL ("Total Vaginal Lenght"): representa a medida entre o hímen e o fundo vaginal posterior.

Os Pontos GH, PB e TVL são dados em números absolutos, pois são medidas de comprimento. Os valores dos pontos obtidos ao exame são representados numa tabela 3x3 (Figura 2). 


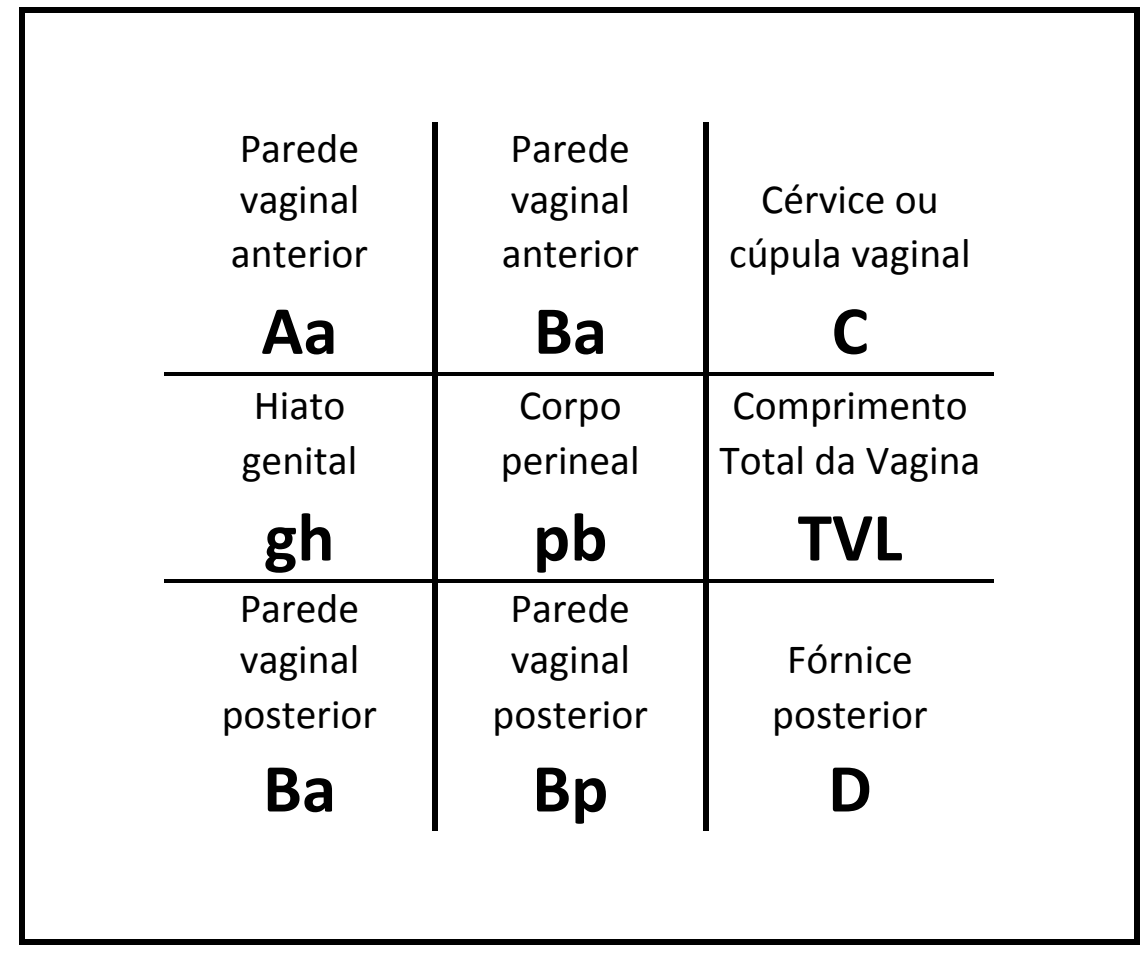

Figura 2 - Tabela 3×3 para registro quantitativo do prolapso genital

Para a avaliação do prolapso da cúpula vaginal, o ponto mais importante é o Ponto $\mathrm{C}$, que informa onde estará a cúpula prolapsada em relação ao plano 0 de referência que é o hímen. Os pontos Ba e Bp avaliam os pontos do maior prolapso das paredes vaginais anterior e posterior, respectivamente. Dependendo da posição dos pontos, o prolapso pode ser dividido em estágios, desde que avaliados na maior protrusão possível. São cinco os estágios desta classificação:

a) Estágio 0: Quando nenhum prolapso é demonstrado. Os pontos $\mathrm{Aa}$, Ba, Ap e Bp estão em -3cm e os Pontos C ou D estão em (TVL 2)cm; 
b) Estágio 1: Não são preenchidos os critérios para estágio 0, e a porção mais distal do prolapso está acima de $1 \mathrm{~cm}$ do nível do hímen (plano >-1);

c) Estágio 2: A porção mais distal do prolapso está entre $1 \mathrm{~cm}$ abaixo e $1 \mathrm{~cm}$ acima do hímen (o valor quantitativo do prolapso está >= -1 e $<=+1)$;

d) Estágio 3: A porção mais distal do prolapso está abaixo de $1 \mathrm{~cm}$ do nível do hímen, porém não protrue mais do que o comprimento total da vagina (TVL) menos $2 \mathrm{~cm}$ (valor quantitativo é $>+1$ porém $<+(T V L-2) c m$ );

e) Estágio 4: É demonstrada eversão total da vagina. A porção mais distal do prolapso (protrue além de TVL $-2 \mathrm{~cm}(>=\mathrm{TVL}-2) \mathrm{cm}$ ). Normalmente o ponto mais distal do prolapso é a cérvice ou a cúpula vaginal.

Complementando o exame físico, a avaliação adequada da qualidade de vida destas mulheres, utilizando-se de um questionário de qualidade de vida validado é necessária. Porém, poucos autores a avaliam adequadamente através de instrumento validado. Vários questionários de qualidade de vida têm sido utilizados, sendo o mais completo (e mais extenso) o Kings Health Questionnaire ou, Questionário de Qualidade de Vida em Prolapso (Anexo 1), que avalia tanto a qualidade de vida em prolapso, quanto suas relações com incontinência urinária e alterações evacuatórias. ${ }^{14,15}$

Com relação ao tratamento do prolapso da cúpula vaginal, o mais utilizado é o cirúrgico. O uso de pessários e diafragma têm uso restrito pelo 
incômodo e desconforto causados. Fica limitado a mulheres sem condições clínicas para o tratamento cirúrgico.

As diversas formas de correção cirúrgica do prolapso da cúpula vaginal têm como base sua fixação a estruturas intra-abdominais fortes. Uma das primeiras técnicas desenvolvidas, a fixação da cúpula no ligamento de Cooper, descrita primeiramente por Sir Astley Cooper em 1841, foi realizada em 1949, com a fixação da cúpula no ligamento e na fáscia adjacente. O primeiro trabalho descrito em 1965 utilizando esta técnica referia haver desvio anterior do eixo vaginal que causava desconforto na atividade sexual. ${ }^{16}$

A sacrocolpofixação abdominal foi descrita pela primeira vez por Frederick E. Lane, em $1962 .^{17} \mathrm{O}$ autor propôs uma técnica onde interpunha uma tela sintética fixa na cúpula vaginal, por meio de pontos com fio inabsorvível sem transfixar a parede vaginal, e os ligamentos sacrais prévertebrais anteriores. Apesar de ser considerada como "padrão-ouro" por alguns autores, a taxa de cura ou melhora varia de $71 \%$ a 99\%. ${ }^{18,19}$ Além de muito variável, o critério de cura não é bem definido, a qualidade de vida das mulheres não foi avaliada e vários autores não citam o que consideram como recidiva do prolapso.

Apesar da taxa de cura ser elevada, as complicações descritas por esta técnica são potencialmente graves. Hemorragias dos vasos pré-sacrais com necessidade de transfusão sanguínea e hematoma abdominal foram descritos em 1\% a 8,9\% dos casos. Infecção, deiscência, abscessos sacrais 
ocorreram em 5,6 a 6\% de incidência; perfuração vesical ou retal e lesões intestinais em 1,6\%. Outras complicações também foram referidas, como formação de fístula vesico-vaginal, herniação intestinal através da tela, lesão nervosa e corrimento vaginal contínuo. ${ }^{20,21}$

Com relação ao uso de materiais sintéticos na correção, as complicações com as telas como extrusão, deslocamento, erosão e infecção foram descritas em $2 \%$ a $12,5 \%$ dos casos. ${ }^{20,21}$ Contrário ao que se pode supor, as infecções desses materiais podem ocorrer após longos períodos da correção cirúrgica. Mattox e cols descreveram a abordagem de 22 mulheres que desenvolveram infecção do material sintético após um e sessenta meses do procedimento cirúrgico, com média de tempo de 8,8meses entre o procedimento e a infecção. ${ }^{22}$ As complicações variaram muito dependendo do material utilizado na fixação da cúpula, da técnica cirúrgica utilizada e de outros parâmetros como o uso de antibioticoterapia, e o fio de sutura, entre outros.

Vários materiais têm sido utilizados na fixação da cúpula ao longo das últimas quatro décadas; o mais antigo foi a tela de polipropileno monofilamentar (Marlex®) cujo índice de extrusão variou de 9 a 20\%. $21,22,23,24$

Porém, muitas variáveis de confusão podem ser detectadas nestes estudos. Alguns autores sugerem que um procedimento mais contaminado, com abertura da cavidade vaginal, por exemplo, favoreceria a infecção e extrusão da tela. Estes autores encontraram entre 8,2\% e 27\% de infecção e 
extrusão da tela quando a histerectomia era realizada concomitantemente com a fixação da cúpula vaginal contra 0 a 4,1\% nas previamente histerectomizadas. ${ }^{24,25,26}$ Estes dados não foram confirmados em estudos posteriores, quando as demais variáveis de confusão haviam sido eliminadas. Brizzolara, em 2003, e Marinkovic, em 2008, não encontraram diferenças entre esses dois grupos, provavelmente porque eliminaram algumas variáveis de confusão ao utilizarem lavagem peritonial com antibióticos e realizar dupla-sutura vaginal sobre a tela. ${ }^{27,28}$

Mais recentemente, uma tela de polipropileno com trançado mais delicado, amolecido e macroporoso foi desenvolvida na tentativa de diminuir as complicações relacionadas à sua extrusão. Com efeito, os estudos sugerem menor índice de extrusão, entre 0 e 1,2\%. ${ }^{28,29,30,31}$

Outros materiais também têm sido empregados para a fixação da cúpula: poliéster, poliéster com cobertura de colágeno reabsorvível, poliéster com cobertura de silicone e teflon expandido revestido com polipropileno (Gore Tex®). Poucos autores têm utilizado estes materiais, portanto os dados relativos à extrusão são baseados em número pequeno de pacientes, não podendo ainda levar a conclusões definitivas. ${ }^{32,33,34}$

Devido às complicações relacionadas à laparotomia, como dor pósoperatória, mobilização tardia com risco de complicações pulmonares e tromboembólicas, dificuldade do acesso cirúrgico em pacientes obesas e risco de infecção, foram desenvolvidas técnicas de correção do prolapso da cúpula por via vaginal. Teria como vantagens diminuir a morbidade 
observada com a via abdominal, principalmente aquela relacionada à dificuldade técnica associada à obesidade e à presença de cirurgias prévias, além da possibilidade de correção concomitante dos outros defeitos vaginais.

A primeira correção cirúrgica do prolapso de cúpula por via vaginal foi relatada por Amreich em 1951, que descreveu a fixação da cúpula prolapsada no ligamento sacroespinhal, considerado pelo autor como o mais forte ligamento de suporte da pelve. ${ }^{35}$

Posteriormente, Richter em 1968 descreveu um complemento dessa técnica, ao fazer pequenas modificações, e tornando-a conhecida como Cirurgia de Richter-Amreich ("vaginaefixatio sacrospinalis vaginalis"). ${ }^{36}$ A técnica foi descrita como a fixação da cúpula no ligamento sacroespinhal através de sutura com fio absorvível e somente no ligamento direito da paciente, levando o terço cranial da vagina acima do plano da placa elevadora do ânus.

Num trabalho de Beer e Kuhn, publicado em 2004, onde se revisaram os trabalhos indexados no período de 1972 a 2002, relacionados a todos os tipos de correção cirúrgica dos prolapsos da cúpula vaginal, os autores encontraram 2390 casos de mulheres submetidas à correção através da fixação no ligamento sacroespinhal. A taxa de cura variou de $67 \%$ a 96,8\%. Porém, muitos trabalhos não faziam referência ao que havia sido considerado como cura ou recorrência do prolapso. Além disso, as maiores 
taxas de cura estavam relacionadas a algum tipo de culdoplastia associada à fixação no ligamento sacroespinhal. ${ }^{20}$

Devido ao desvio posterior e lateral direito da cúpula vaginal que ocorre na correção cirúrgica do prolapso pela fixação no ligamento sacroespinhal, alguns autores notaram haver uma predisposição ao longo do tempo para o surgimento ou recidiva de defeitos da parede vaginal anterior. Este ocorria, em geral, devido à mudança do eixo de força das pressões abdominais, antes dirigidas somente à cúpula e que posteriormente passava a se apresentar também na parede vaginal anterior. ${ }^{37}$ Apesar de muitos autores não especificaram ou quantificarem a presença do prolapso anterior pós-correção da cúpula vaginal, outros a referem entre 13,3\% e 92\%. A presença de dor pélvica ipsilateral à fixação, por períodos superiores há um ano, foi outra complicação descrita em $6,1 \%$ dos casos, a qual se tornou crônica em 0,7\%. ${ }^{38,39,40}$

As queixas sexuais mais freqüentes, como dispareunia, relacionadas ao desvio do eixo vaginal, tanto na mulher quanto no parceiro, foram relatadas entre $5,9 \%$ e $16 \%$. Já Lovatsis observou 5,2\% de dispareunia de novo. ${ }^{38,41}$

Procurando uma forma de fixação da cúpula vaginal mais anatômica e funcional possível, Petros, em 1990, elaborou a Teoria Integral, segundo a qual os sintomas de perda urinária aos esforços, os sintomas de urgência e o esvaziamento vesical anormal eram apenas manifestações 
secundárias à flacidez vaginal ou ao relaxamento dos seus ligamentos de suporte. $^{42}$

Segundo Petros, a pelve possui três forças direcionais que comprimem a vagina contra seus ligamentos suspensórios, de forma a ancorar os órgãos pélvicos. A primeira acha-se representada pelos ligamentos pubo-uretrais, que quando contraídos ocluem a uretra impedindo o fluxo urinário. A segunda, com direção posterior, está representada pelos ligamentos útero-sacros, que ao se contraírem estiram a cúpula vaginal no sentido posterior, ocluindo o fundo-de-saco posterior, impedindo assim a herniação dos órgãos pélvicos por esta via. E a terceira força, constituída pela musculatura longitudinal do ânus, que ao se contrair traz a parede vaginal posterior no sentido inferior, ocluindo a luz vaginal. ${ }^{43}$

Lesões no tecido conectivo destas estruturas geram defeitos que podem ser classificados em três zonas de flacidez: anterior, mediana ou apical e posterior. A zona de flacidez apical estaria relacionada aos defeitos ou ruptura da fáscia endopélvica e do arco tendíneo desta fáscia e, a posterior, estaria associada ao enfraquecimento dos ligamentos útero-sacros e às alterações da função evacuatória. Segundo essa teoria, essas três forças são funcionalmente inter-relacionadas e afetam umas às outras. Além disso, divididas em três zonas, em situações de aumento da pressão abdominal favoreceriam a oclusão dos pontos de fraqueza das paredes vaginais, impedindo a ocorrência de prolapso dos órgãos pélvicos. ${ }^{44}$ A correção de um nível de defeito em qualquer uma das forças, sem corrigir 
as demais, proporcionaria posteriormente o aparecimento do defeito em outro nível. ${ }^{45}$

Baseado em sua teoria, o autor, em 2001, descreveu a correção do prolapso da cúpula vaginal com a técnica da sacropexia infracoccígea. Os defeitos do nível 1, segundo De Lancey, seriam corrigidos pela interposição de faixa sintética, onde utilizou nylon. Para os do nível 2 seria criada uma ponte de mucosa vaginal, de forma a reforçar a fáscia retovaginal. Os do nível 3 seriam corrigidos por meio da reconstituição do corpo perineal. Para a fixação do nível 1, o autor introduzia a faixa de nylon no espaço pararretal através de uma incisão mediana e infracoccígea, posterior à borda anal, com cerca de 1cm, e por meio desta incisão, inseria um tunelizador por onde a faixa era introduzida lateralmente ao reto, penetando profundamente a fossa isquioretal e transfixando a placa da musculatura elevadora do ânus, guiada em direção à espinha isquiática. Posteriormente, exteriorizava na submucosa vaginal, na direção do ligamento útero-sacro, e à cúpula vaginal, onde era fixada por sutura que também transfixava os ligamentos cardinais e era mantida livre de tensão. Em movimento em $U$, a faixa retornava pelo lado contralateral, sendo exteriorizada na borda anal novamente. Este procedimento foi chamado de sacropexia infracocígea. O objetivo da faixa era reforçar os ligamentos úterosacros fracos ou rotos pela criação de um neo-ligamento de faixa de nylon. As pacientes foram seguidas por um período de 1 a 4,5 anos e a taxa de recidiva de prolapso foi de $6 \% .{ }^{46}$ 
A complicação principal foi a extrusão da faixa de nylon em 5,3\% dos casos; devido a ela, o autor passou a usar faixa de polipropileno, o que reduziu o índice de extrusão da faixa para zero, como demonstrado em estudos posteriores.

Revisando os trabalhos publicados entre 2002 e 2008 de correção do prolapso da cúpula vaginal utilizando a técnica de colpopexia infracocígea, encontra-se taxa de cura de 82,7 a 97,2\%, com tempo médio de seguimento de 16,6 meses. Houve significativamente maior extrusão da faixa quando se utilizou polipropileno multifilamentar (9 a 20\% de extrusão) em comparação à tela de polipropileno monofilamentar e macroporosa (0 a $5,7 \%)^{47,48,49,50,51,52,53,54}$

Estudo de Jelovsek e colaboradores, em seis cadáveres frescos, analisando o procedimento cirúrgico descrito por Petros, demonstraram as relações anatômicas da passagem do tunelizador com as principais estruturas vasculares, musculares e ósseas da pelve. Confirmou as afirmações de muitos autores, incluindo o próprio Petros, de que a sacropexia infracoccígea não oferecia risco de lesões vasculares maiores. Os autores demonstraram uma distância de $2,1 \mathrm{~cm}$ a 3,4cm do tunelizador ao canal de Alcock, por onde saem os principais vasos pudendos. A maior proximidade foi encontrada com o reto, onde a menor distância encontrada com o tunelizador foi de $2 \mathrm{~mm} .{ }^{55}$ Além isso, o aspecto cônico e não cortante do tunelizador divulsiona as estruturas no espaço isquiorretal, diminuindo a chance de lesão de estruturas nobres. 
Têm se buscado cada vez mais métodos cirúrgicos menos invasivos, com maior facilidade técnica e melhor preservação possível da anatomia da pelve feminina. Nesse aspecto, a sacropexia infracoccígea constitui procedimento considerado minimamente invasivo, com curva de aprendizado relativamente curta e que evita as complicações das abordagens abdominais sem alterar significativamente a anatomia.

As dúvidas inerentes ao melhor método de correção cirúrgica do prolapso da cúpula vaginal, aliados à enorme variedade de procedimentos diferentes hoje empregados, motivaram a realizar este estudo. 
2. Proposição 
Propusemo-nos a avaliar os resultados do tratamento cirúrgico de mulheres portadoras de prolapso da cúpula vaginal pela técnica da sacropexia infracoccígea, analisando os seguintes parâmetros:

1) Clínicos (queixas clínicas, exame ginecológico e recidiva do prolapso);

2) Qualidade de vida; 
3. Métodos 


\subsection{Casuística}

Dentre as mulheres portadoras de prolapso genital matriculadas no Setor de Uroginecologia da Disciplina de Ginecologia do Hospital das Clínicas da Universidade de São Paulo (HCFMUSP), foram selecionadas 98 mulheres com prolapso de cúpula vaginal, associado ou não aos prolapsos das paredes vaginais anterior e posterior, no período de março de 2004 a fevereiro de 2008. Destas, foram selecionadas 36 que apresentavam prolapso de cúpula vaginal estágio 3 e 4 segundo o sistema $\mathrm{POP}-\mathrm{Q}^{13}$. Entre elas, trinta incluíam-se no estágio 4 e seis no estágio 3 no momento da seleção.

A idade variou entre 47 e 82 anos, com média de 68,7. Em relação à paridade, o número de partos vaginais oscilou de 1 a 4 e o de partos cesáreas de 0 a 1. Todas as mulheres eram brancas, pós-menopáusicas e não faziam uso de terapia hormonal.

O peso variou de 43 a $91 \mathrm{Kg}$, com média de 67,6. O Índice de Massa Corpórea (IMC) oscilou de 19,6 a 37,2Kg/m², com média de 27,7.

Todas as mulheres assinaram o Termo de Consentimento Livre e Esclarecido (Anexo A).

O estudo foi aprovado pela Comissão de Ética e Pesquisa Médica do Hospital das Clínicas da Faculdade de Medicina da Universidade de São Paulo (CAPPesq). 


\subsection{Métodos}

Foi realizado estudo prospectivo em mulheres portadoras de prolapso de cúpula vaginal, submetidas à correção cirúrgica pela técnica da Sacropexia Infracoccígea. Foram acompanhadas em intervalos de um, três, seis, doze meses e, a seguir, anualmente, no pós-operatório, por um período de tempo que oscilou entre 10 e 55 meses, com média de 30,9 meses.

\subsubsection{Avaliação clínica}

Foram coletados os dados da anamnese e do exame ginecológico. As mulheres referiam sensação de peso, bola na vagina e/ou algo se exteriorizando pelo intróito vaginal. Outras queixas incluíam dificuldade de esvaziamento vesical, com ou sem necessidade de redução do prolapso, e/ou dificuldade de evacuação. Além destes, muitas relatavam comprometimento da vida social com reclusão ao lar devido ao constrangimento do aparecimento do prolapso quando fosse necessário uso de maiôs e calças e desconforto ao sentar pela compressão da vagina prolapsada. 


\subsubsection{Exame Ginecológico}

Todas foram classificadas quanto ao grau do prolapso segundo o sistema $\mathrm{POP}-\mathrm{Q}^{13}$. Após o exame, a autora deste trabalho aplicou o Questionário de Qualidade de Vida em Prolapso - Versão II. ${ }^{14,15}$

Pelo exame ginecológico foram selecionados os pontos $\mathrm{C}$, para avaliação do nível da fixação da cúpula vaginal, e Ba e Bp para avaliação do grau de prolapso das paredes vaginais anterior e posterior, respectivamente.

Considerou-se como critério de cura do prolapso da cúpula vaginal quando no pós-operatório o ponto C permaneceu cranial ao nível -3 avaliado no exame ginecológico. Melhora clínica foi considerada quando o ponto C permaneceu entre 0 e -2 .

Em relação ao defeito anterior, a correção fascial foi sítioespecífica, sem tela e realizada somente nas mulheres com estágio superior ou igual a 3.

\subsubsection{Questionário de Qualidade de Vida em Prolapso}

O Questionário de Qualidade de Vida em Prolapso - versão II, validado na Itália, e em processo de validação no Brasil (Anexo B), tem sete domínios de percepção: percepção geral em saúde, impacto do prolapso, 
limitação de função, limitações físicas e sociais, relações pessoais, emoções e sono/energia. ${ }^{14,15}$

Com exceção da primeira e da vigésima - quinta pergunta do primeiro domínio (Percepção Geral de Saúde - Como está a sua saúde hoje?), que apresenta cinco opções de resposta, todas as outras questões dos outros domínios, tinham somente quatro opções de resposta.

Para graduar o Questionário de Qualidade de Vida, utilizamos uma pontuação para cada pergunta. Para a $1^{\mathrm{a}}$ e a $25^{\mathrm{a}}$ pergunta do $1^{\circ}$ domínio, a graduação ficou assim estabelecida:

1) Muito boa/uma vez ao dia: (0)

2) Boa/mais de uma vez ao dia: (1)

3) Regular/a cada dois dias: (2)

4) Ruim/a cada três dias: (3)

5) Muito Ruim/uma vez por semana: (4)

Já para as demais perguntas de todos os outros domínios, adotou-se:

1) não: pontuação: (0)

2) um pouco/às vezes/um pouco fraco: (1)

3) mais ou menos/várias vezes/mais ou menos fraco: (2)

4) Muito/bastante/sempre: (3)

No final de cada conjunto de perguntas de um domínio, os pontos eram somados, estabelecendo-se uma pontuação para cada domínio. Ao término de cada questionário, os pontos de todos os domínios foram 
somados, totalizando a pontuação geral dada pela paciente. $\mathrm{O}$ escore 0 representa a melhor pontuação.

O questionário de qualidade de vida foi aplicado nos períodos pré e pós-operatório, sendo a avaliação pós-operatória realizada com 3, 6, 12 meses e, a seguir, anualmente. Estas pontuações foram comparadas nos períodos pré e pós-operatório. Redução de $50 \%$ ou mais na pontuação entre o período pré e o pós-operatório foi considerada como sendo melhora da qualidade de vida.

\subsubsection{Técnica Cirúrgica da Sacropexia Infracoccígea}

O preparo pré-operatório incluiu tricotomia abdominal e perineal e enteroclisma.

A antibioticoprofilaxia foi realizada no momento da indução anestésica, administrando-se cefalotina (1g) e metronidazol (400mg) por via endovenosa $(E V)$. No período pós-operatório manteve-se cefalotina EV (500mg de 6/6hs) e metronidazol EV (400mg 8/8hs por 24hs).

A anestesia realizada foi bloqueio intradural e, a seguir, foram colocadas em posição ginecológica com hiperflexão das coxas.

A antissepsia da parede abdominal, da região vulvoperineal e da vagina foi realizada com solução de iodopovidona a 1\%, com exceção das pacientes alérgicas ao iodo, nas quais se utilizou solução de clorexidina aquosa e degermante, na proporção de $50 \%$ cada. 
Os campos cirúrgicos foram dispostos de maneira padronizada para cirurgia abdominoperineal. Foi feita cateterização vesical com sonda de Foley número 12.

Realizou-se, inicialmente, perineotomia, seguida de incisão longitudinal mediana da mucosa da parede vaginal posterior até a cúpula vaginal, com exposição da área retal herniada. Em seguida, realizaram-se os seguintes tempos:

1. Dissecção da submucosa vaginal lateralmente, ultrapassando o ponto de rotura da fáscia reto-vaginal, seguindo profundamente até a espinha isquiática, expondose a porção coccígea da musculatura elevadora do ânus e o ligamento sacro-espinhoso, bilateralmente;

2. Incisou-se, em uma extensão de $1 \mathrm{~cm}$, em posição $3 \mathrm{~cm}$ lateral e posterior à borda anal, formando ângulo de $90^{\circ}$ bilateralmente;

3. Introduziu-se o tunelizador com fio guia interno através dessa incisão próximo à borda anal, numa extensão de cerca de $4 \mathrm{~cm}$, perfurando a musculatura elevadora do ânus. Com guia digital, orientou-se o tunelizador na direção da espinha isquiática, $1 \mathrm{~cm}$ medial a ela e, em seguida, exteriorizou-se o tunelizador na submucosa vaginal. Após, retirou-se o tunelizador deixando o guia em posição de tracionar a faixa. O mesmo procedimento foi realizado na região contralateral. Posicionou-se a faixa de polipropileno 
monofilamentar e macroporosa através do guia, que foi introduzida na borda anal esquerda, exteriorizou-se na vagina. Pelo guia contralateral, tracionou-se a faixa no lado direito da paciente até exteriorização pela incisão lateral e posterior à borda anal;

4. A faixa foi fixada nos paramétrios bilateralmente, com fio de ácido poliglicóico 0 , e com um ponto central na cúpula vaginal;

5. Confeccionou-se um retalho retangular de tela de polipropileno monofilamentar macroporosa de $7 \times 3 \mathrm{~cm}$, sendo que uma extremidade foi fixada com fio de ácido poliglicóico 0 na fita de polipropileno colocada na cúpula vaginal. A outra extremidade fixou-se com fio de ácido poliglicóico 0 na submucosa vaginal, transfixando-se a musculatura elevadora do ânus bilateralmente;

6. Revisão da hemostasia;

7. Aproximaram-se, sem ressecção da mucosa vaginal, as bordas da parede vaginal com fio de Catgut 0 simples, com sutura contínua ancorada;

8. Aproximou-se a musculatura bulbocavernosa e transversa superficial do períneo com ponto de ácido poliglicóico 0 , quando necessário;

9. A pele do corpo perineal foi aproximada com pontos separados de Catgut 0 simples; 
10. A fita de polipropileno foi tracionada e exteriorizada nas bordas anais bilateralmente e mantida em posição sem tensão;

11. Seccionou-se a fita junto à pele, sendo esta suturada com fio de Nylon 3-0 ou 4-0;

12. Na presença de cistocele, procedeu-se à correção sítioespecífica;

13. A sondagem vesical foi mantida $24 \mathrm{hs}$.

\subsubsection{Análise Estatística}

Os dados obtidos foram analisados estatisticamente e divididos em duas partes:

a) Para a avaliação da evolução do exame físico pré e pósoperatório segundo o sistema POP-Q, foi utilizado o Teste de Mc Nemar com nível de significância de 5\% (95\% de confiança). Este permite detectar quando há mudança de estado numa classificação e se esta mudança foi significante. Quando não foi possível aplicar este teste, usou-se o Teste do Sinal, que permite dizer se a intervenção foi significativa com relação à melhora ou piora; 
b) Para avaliar o questionário de qualidade de vida e suas subescalas, comparando os momentos inicial e 3, 6, 12, 24, 36, 48 e 60 meses, foi realizada análise de Variância (ANOVA), com medidas repetidas, com nível de confiança de 95\% $(p<0,05)$. 
4. RESULTADOS 


\subsection{AVALIAÇÃO CLÍNICA DO PROLAPSO}

Após o procedimento cirúrgico, todas as mulheres referiram melhora dos sintomas do prolapso e da qualidade de vida, como pode ser demonstrado no Questionário de Qualidade de Vida em Prolapso. Todas relataram melhora na vida social e no desconforto vulvar. Houve uma única recidiva do prolapso da cúpula vaginal após 24 meses.

Com relação aos prolapsos anteriores, observaram-se 4 casos de recidiva do prolapso da parede vaginal anterior, perfazendo $11,1 \%$ de recidiva. O Anexo C ilustra a evolução do Ponto $\mathrm{Ba}$, que representa o ponto de maior prolapso da parede vaginal anterior.

Com relação à parede vaginal posterior, não encontramos nenhuma recidiva do prolapso. Os dados relativos ao ponto $\mathrm{Bp}$, que representa o ponto de maior prolapso da parede vaginal posterior, estão demonstrados no Anexo D. 


\subsubsection{Exame ginecológico: avaliação da cúpula vaginal}

O Ponto C variou do valor médio de +6 no período pré-operatório, para -6,5 no período pós-operatório, considerando-se 24 meses de evolução (Gráfico 1) (Anexo D).

Grafico 1 - Evolução do Ponto C até 24 meses de pós-operatório

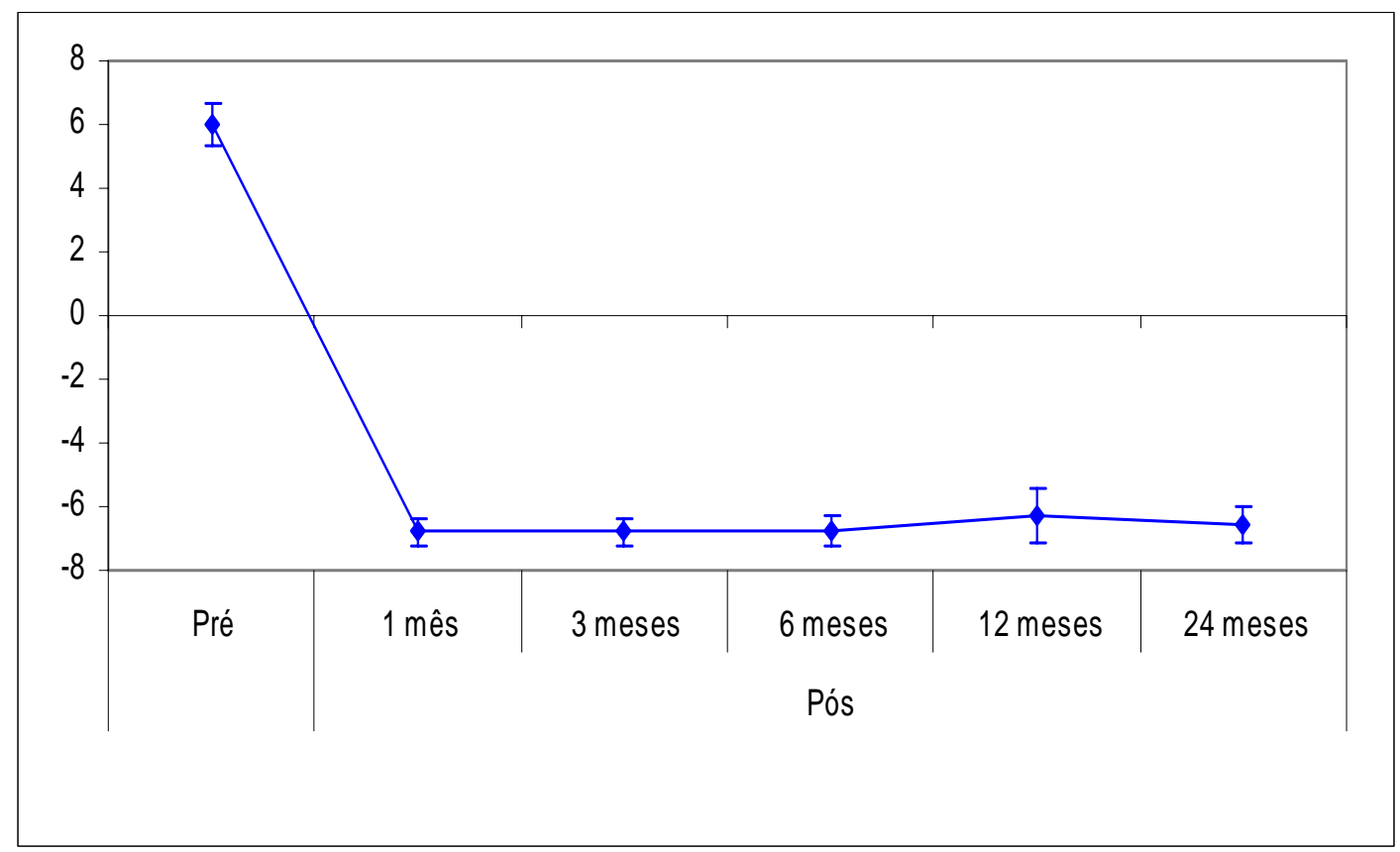

Quando se analisou o tempo de evolução de 48 meses, a média do ponto C no período pós-operatório foi de $-5,80$ (Gráfico 2). 
Gráfico 2 - Evolução do Ponto C até 48 meses de avaliação pós-operatória

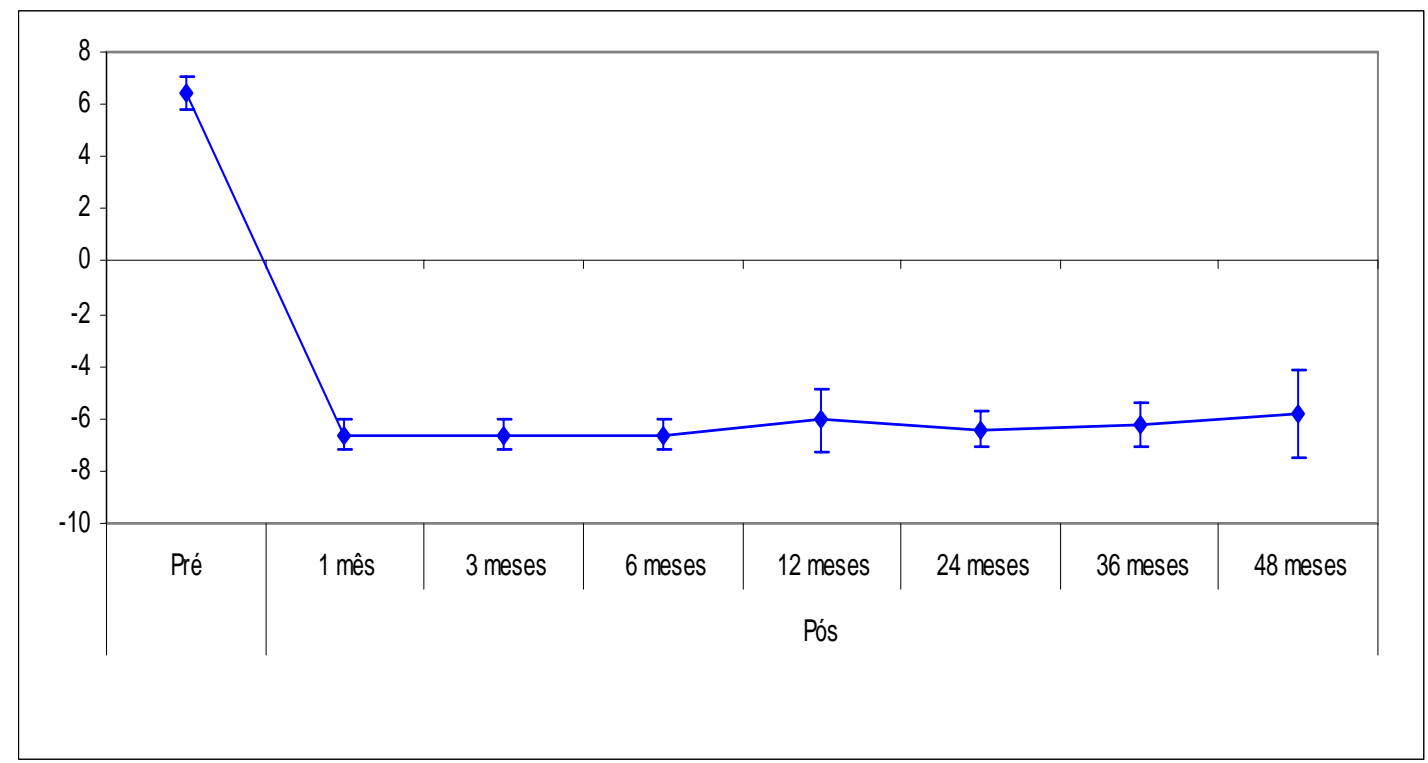

A análise estatística permitiu concluir que a variação entre os momentos pré e pós-operatórios foram significantes $(p<0,05)$. Não houve variação entre os momentos pós-operatórios entre si.

Estes dados mostram que o índice de melhora clínica do prolapso apical foi de $97,2 \%$, após tempo médio de observação de 30,9 meses. O Anexo E ilustra a casuística completa e a evolução do Ponto C em cada caso. 


\subsubsection{QUESTIONÁRIO DE QUALIDADE DE VIDA EM PROLAPSO}

\subsubsection{Somatória de todos os domínios}

A análise da somatória de todos os domínios do questionário de qualidade de vida, revelou redução significativa da pontuação entre as avaliações pré e pós-operatórias (ANOVA - p<0,05).

Pode-se concluir que houve diferença significativa entre os momentos inicial (pré-operatório) e as avaliações após 3, 6, 12 e 24 meses no pós-operatório. Não houve diferenças na comparação entre as avaliações pós-operatórias entre si $(p<0,05)$ - (Gráfico 3).

Gráfico 3 - Evolução da pontuação do Questionário de Qualidade de Vida em Prolapso - somatório de todos os domínios

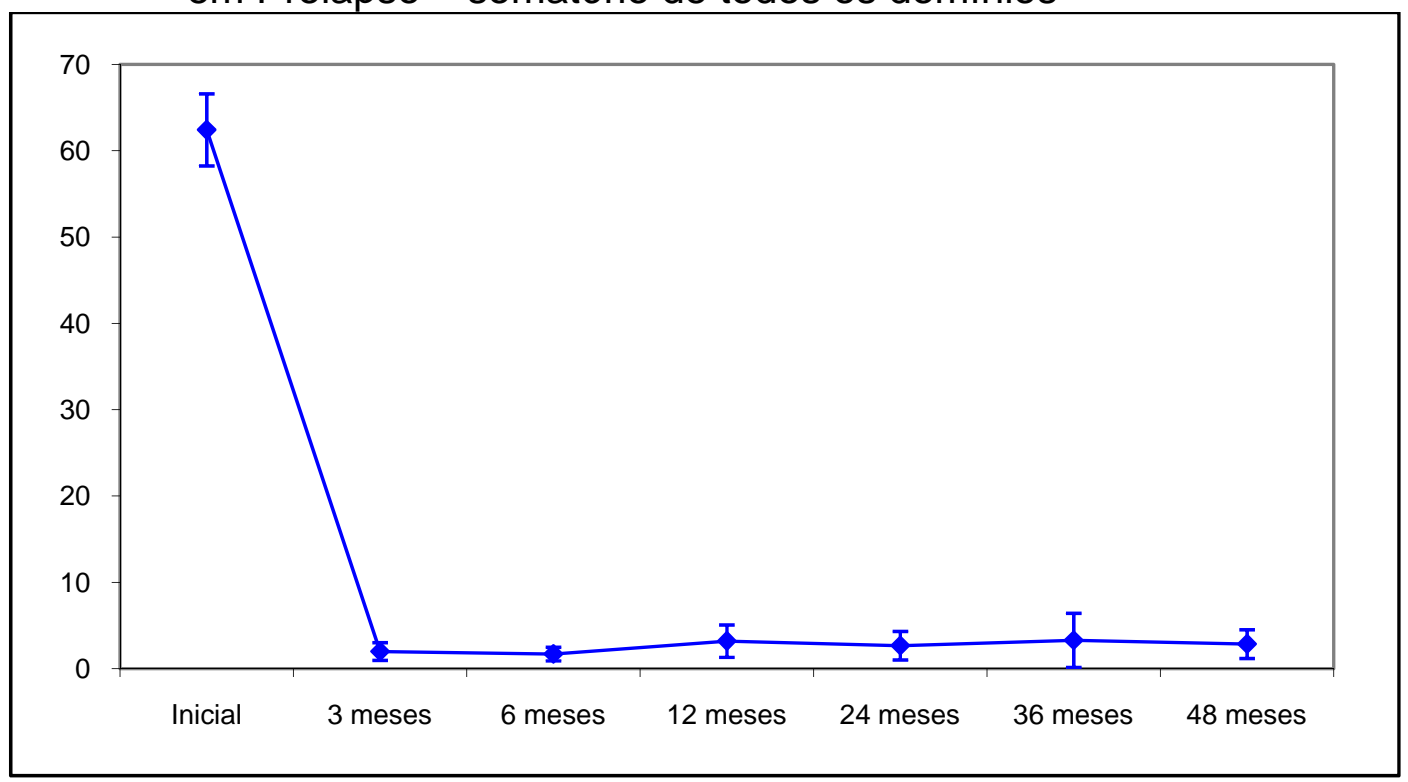


A análise de comparações múltiplas mostrou que a pontuação tem a seguinte hierarquia: a inicial foi significativamente maior que a de três meses após a cirurgia, mantendo-se inalterada nos períodos 6, 12 e 24 meses de acompanhamento pós-operatório. De igual modo, não houve mudança nas pontuações das avaliações posteriores, até a última avaliação em cada caso.

\subsubsection{Evolução de cada domínio do questionário}

O Gráfico 4 mostra a evolução das pontuações de cada um dos sete domínios do questionário de qualidade de vida. 
Gráfico 4 - Evolução da pontuação de cada domínio do Questionário de Qualidade de Vida em Prolapso

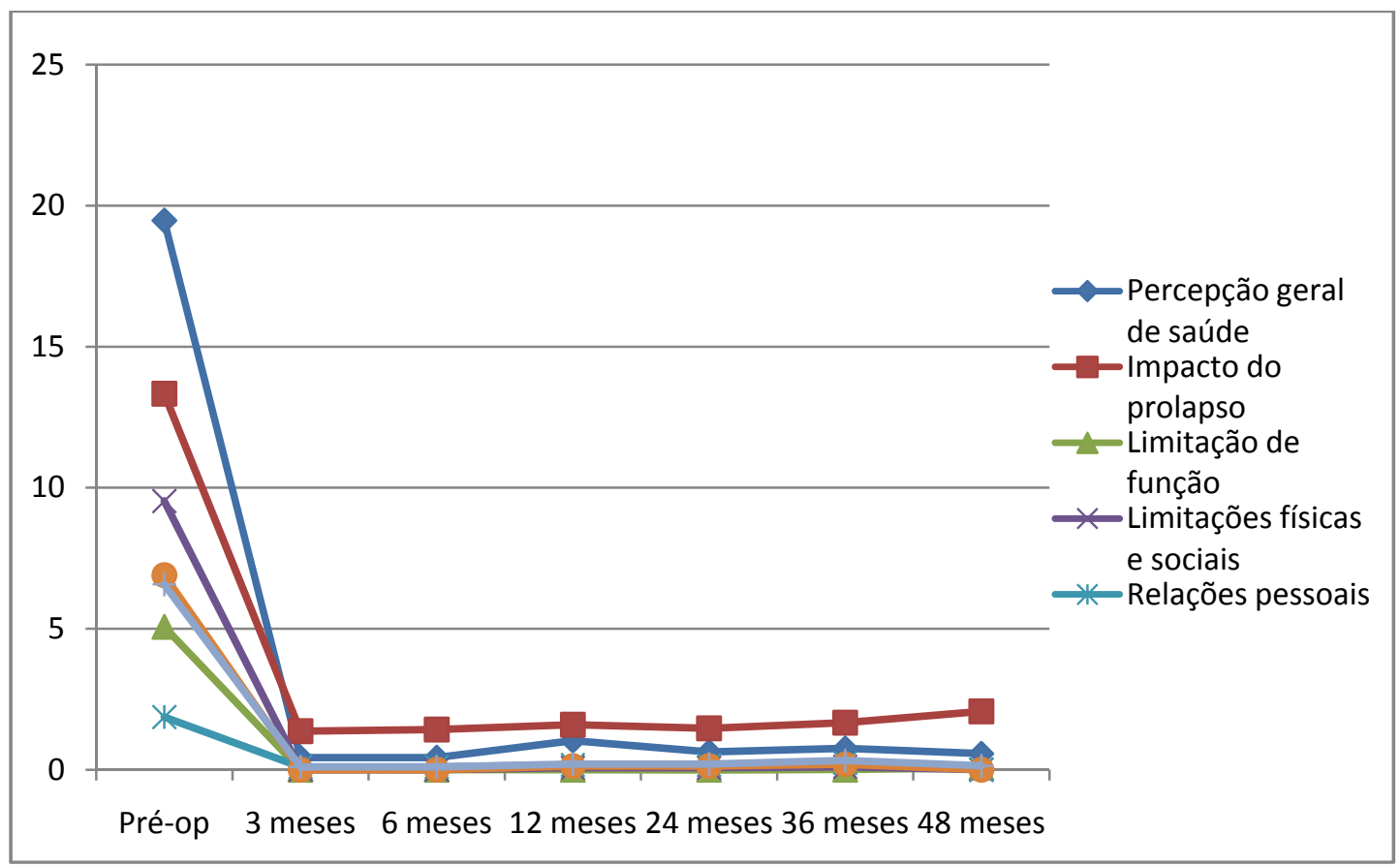

Houve redução significativa da pontuação em cada um dos domínios $(p<0,05)$. A análise das comparações múltiplas revelou que a pontuação da avaliação pré-operatória foi significativamente maior que a de três meses após a cirurgia, mantendo-se inalterada 6, 12 e 24 meses de pós-operatórios. 
5. DISCUSSÃO 
Este trabalho teve como objetivo avaliar os resultados da correção do prolapso de cúpula vaginal utilizando a técnica da sacropexia infracoccígea. No momento da elaboração deste trabalho, em 2003, somente quatro trabalhos haviam sido publicados com esta técnica, sendo que dois eram de Petros, que também descrevia o procedimento. A primeira série de casos publicada por Petros foi em $2001^{46}$ e, posteriormente, por Farsworth em 2002. ${ }^{47}$

A taxa de cura/melhora que encontramos neste trabalho, considerando-se um tempo de evolução médio de 30,9 meses (10 a 55 meses), foi de 97,2\%. Registramos recidiva de apenas um caso após 24 meses de evolução, ou seja, índice de 2,8\%.

Os dados de literatura assinalam que a taxa de recidiva varia entre zero e 17,3\%, com tempo médio de seguimento de 16,5 meses (1 a 45 meses). Porém, muitas ressalvas podem ser feitas à análise comparativa de nossos resultados com estes dados.

A maioria dos trabalhos realizados com esta técnica selecionou tanto mulheres histerectomizadas quanto aquelas com prolapso uterino, neste último efetuando correção com preservação uterina. Não sabemos se a presença do útero pode influenciar, de forma positiva ou negativa, na taxa de recidiva do prolapso.

Além disso, os autores utilizaram mulheres tanto com prolapso em estágios iniciais (estágios 1 e 2), quanto aqueles em estágios mais 
avançados (3 e 4). Neste aspecto, não se pode assegurar, com precisão, se o índice de recidiva nos estágios iniciais será igual aos dos estágios mais avançados. Poderia haver certa preservação do complexo cardinalúterossacral e do tecido conectivo nas fases mais iniciais, impedindo a evolução do prolapso.

Com relação à sintomatologia, não existem dados nos trabalhos que diferenciem os sintomas nos estágios iniciais $(1,2)$ dos estágios avançados $(3,4)$. Provavelmente, a mulher com prolapso total da cúpula deve apresentar mais incômodo do que a que apresenta prolapso sem exteriorização da cúpula vaginal.

Com relação ao tempo de evolução, um único autor, Deffieux, em 2009, mostrou tempo de seguimento longo, média de 32 meses (19 a 45 meses). ${ }^{48}$ Porém, o autor não informou separadamente o tempo de evolução das mulheres com prolapso de cúpula e o das que preservaram o útero. Aliás, foram operadas 87 pacientes das quais somente 8 eram histerectomizadas e apresentavam prolapso da cúpula vaginal.

Apenas o estudo de Farnsworth, em 2002, incluiu somente mulheres histerectomizadas. O autor não utilizou o POP-Q na classificação do prolapso, mas empregou uma classificação semelhante à de Baden. Considerou como estágio 2 quando o prolapso atingia o intróito vaginal e, estágio 3, quando o ultrapassava. Observou recidiva de 9\%, com tempo de seguimento médio de 12 meses (2 a 24 meses). Contudo, não foi avaliada a qualidade de vida. ${ }^{47}$ 
Todos estes desvios metodológicos impedem que façamos a comparação direta de nosso estudo com os dados de literatura disponíveis. Portanto, nosso trabalho é inédito no que concerne à análise exclusiva da correção do prolapso da cúpula vaginal, com um tempo de seguimento mais longo.

5.1 Avaliação do prolapso da parede vaginal anterior

Os dados de literatura indicam que a técnica de fixação da cúpula vaginal no ligamento sacroespinhal favorece a recidiva do prolapso da parede vaginal anterior, provavelmente por desviar o eixo da cúpula vaginal posterior e lateral, aumentando a pressão exercida na parede vaginal anterior. Os índices de recidiva podem variar de 20 a 92\%. ${ }^{20}$

Acredita-se que a correção pela técnica da sacropexia infracoccígea, por não desviar o eixo vaginal, propicie menor índice de recidiva da cistocele. Tayrac, em 2008, comparando essas duas técnicas, encontrou recorrência da cistocele após a sacropexia infracoccígea de 4,8\% enquanto a taxa com a fixação no ligamento sacroespinhal foi de $25 \%$, o que corrobora essa teoria. 54

A explicação plausível para o menor índice de recidiva do prolapso da parede vaginal anterior com a técnica da sacropexia infracoccígea em relação à fixação da cúpula no ligamento sacroespinhoso, seria que esta 
última mantém a cúpula em situação mais posterior por estar fixada no sacro. A fixação vaginal a primeira técnica manteria a cúpula em um nível mais elevado, somente presa pela faixa, de modo a simular os ligamentos útero-sacros, e dividindo parcialmente a pressão abdominal entre as paredes anterior, posterior e apical.

Existem poucos dados na literatura que relatem a recidiva do prolapso da parede vaginal anterior após a correção pela técnica da sacropexia infra-coccígea. Somente três autores publicaram dados relacionados à recorrência da cistocele. Petros, quando descreve sua primeira série de casos, anotou recidiva da cistocele de até $16,2 \%$ em dois anos. ${ }^{49}$ Outros autores referem recorrência entre 3,5 e 4,8\%, porém, não descrevem a técnica utilizada para a correção. ${ }^{47,54}$

Em nosso trabalho, tivemos quatro casos de recidiva parcial do prolapso da parede vaginal anterior, que representa uma taxa de 11,1\% de recidiva (Anexo C), compatível com os dados encontrados na literatura. Como nos propusemos a estudar o prolapso da cúpula vaginal, não optamos por corrigir cistoceles discretas, no estágio 1 do POP-Q. É provável que o reforço da cúpula vaginal e da parede posterior, observado com a técnica da sacropexia infracoccígea, por nós utilizada, permitiria que a fraqueza da parede vaginal anterior, mesmo que discreta, com o aumento da pressão abdominal, evolua para o rompimento da fáscia endopélvica, gerando recorrência do prolapso. 
5.2 Avaliação do prolapso da parede vaginal posterior

O grau de prolapso da parede vaginal posterior foi avaliado através dos pontos Ap e Bp, este último representando o maior prolapso da parede vaginal posterior. Observamos que o Ponto $\mathrm{Bp}$ evoluiu de média +6 no exame pré-operatório para -2,9 na avaliação pós-operatória ao longo de 48 meses de acompanhamento (Anexo D).

Esta redução foi significativa e se manteve constante nas diferentes avaliações pós-operatórias, ou seja, obtivemos melhora significativa do prolapso da parede vaginal posterior. Quase nenhum autor faz referência à recidiva desse tipo de prolapso, separadamente da cúpula, após correção com esta técnica cirúrgica.

Em comparação com outras técnicas, como a fixação no ligamento sacro-espinhal, que mostra recidiva de até $92 \%$ de prolapso da parede vaginal posterior, faz com que o cirurgião realize a culdoplastia posterior para evitar a recidiva desse tipo de prolapso. ${ }^{20}$ 


\subsection{Complicações}

\subsubsection{Complicações Peri-operatórias}

Não são descritas grandes complicações com este procedimento. Entre elas a perfuração retal ocorreu no início do desenvolvimento da técnica, quando Petros realizava somente uma incisão infra-anal única (no sulco interglúteo) para a inserção do tunelizador. Apesar de trabalho com dissecção em cadáveres mostrar uma proximidade muito grande com a parede retal na passagem do tunelizador, numa distância mínima de $2 \mathrm{~mm}$, não há nenhum caso descrito na literatura de perfurações retais após as mudanças efetuadas na técnica original descrita por Petros em 2001. ${ }^{46}$ Não houve perfuração vesical nem retal em nosso trabalho.

Não houve nenhum caso de sangramento intra-operatório com necessidade de transfusão sanguínea. Nenhum procedimento estendeu-se por mais de 90 minutos de intervenção. Não foram detectados hematomas importantes no pós-operatório que necessitasse de intervenção.

Todas as mulheres foram mantidas com sondagem vesical no pósoperatório imediato. Nenhuma ficou sondada por mais de um dia após o procedimento. Não houve retenção urinária em nenhuma paciente.

Não ocorreu nenhum caso de infecção pós-operatória. 


\subsubsection{Incontinência Urinária de Esforço}

Houve um caso de aparecimento de incontinência urinária de esforço (IUE) após 36 meses de evolução pós-operatória. Esta paciente foi submetida à correção de IUE com 38 meses de evolução, e mantém-se assintomática após 4 meses da correção da IUE.

\subsubsection{Extrusão da faixa/rejeição}

A principal complicação relatada em literatura é a extrusão da faixa, descrita em até $21,1 \%$ dos casos. Os relatos de complicações existentes descrevem o uso da primeira faixa utilizada por Petros, que era de Nylon e posteriormente uma faixa que era feita de polipropileno multifilamentar e microporosa, que permitia uma maior infiltração de bactérias devido ao microporo, mas impedia a penetração de macrófagos, e dessa forma causava maior índice de extrusão da faixa. 47,48,50 Posteriormente adotou-se a faixa de polipropileno monofilamentar e macroporosa, para permitir a passagem dos macrófagos pelos poros. Porém, faltam dados de literatura que descrevam a utilização desta faixa na sacropexia infracoccígea e que correlacionem o índice de extrusão. Na nossa casuística não tivemos nenhum caso de extrusão. ${ }^{47,48,49,50,51}$ 


\subsubsection{Dor relacionada ao procedimento cirúrgico}

A dore relacionada ao procedimento ocorreu somente nos primeiros 2 dias pós-cirurgia e foi tratadas com sintomáticos (dipirona e antiinflamatórios não esteroidais).

Houve uma paciente que teve de dor tipo nevralgia na face interna da coxa esquerda, a qual se iniciou um a dois dias após o procedimento cirúrgico e se manteve por cerca de 20 dias. Foi controlada com antiinflamatórios não esteroidais e teve remissão espontânea após este período. A mesma foi avaliada por 44 meses após a correção cirúrgica e manteve-se assintomática.

\subsubsection{Sexualidade}

Das 36 pacientes operadas, 9 apresentavam vida sexual ativa antes da intervenção e a mantiveram após. Oito mulheres não relataram qualquer alteração na vida sexual após o procedimento, tendo relatado como normal.

Uma paciente relatou que, apesar de não apresentar dispareunia, sentia "algo estranho na relação sexual". Apesar do parceiro não apresentar queixas, a paciente referiu sentir como uma tração no fundo vaginal no momento da relação sexual que a incomodava um pouco apesar de não sentir dor. 
A sexualidade é muito pouco citada nos trabalhos publicados até aqui com esta técnica de correção, talvez pela idade em geral avançada das pacientes que procuram os centros de saúde para cura desta moléstia. Porém, com a modernização e introdução da mulher nos diversos setores da economia, a sexualidade feminina têm se aflorado e não mais colocada em plano secundário ou associada à religiosidade.

Dessa forma, correções dos prolapsos vaginais que respeitem a anatomia e proporcionem vida sexual normal tem sido alvo de grande discussão e procura. Acreditamos que o caráter mais anatômico deste procedimento, que não permite desvios vaginais laterais ou posteriores, pode resultar numa vida sexual adequada à mulher. Devido ao pequeno número de mulheres com vida sexualmente ativa neste trabalho, estudos posteriores com enfoque maior na sexualidade devem ser elaborados para melhor responder a estas questões.

\subsubsection{Qualidade de vida}

Com relação à qualidade de vida, este é o primeiro trabalho realizado dentre as publicações existentes que fez avaliação da qualidade de vida com questionário validado. Em todos os domínios, incluindo o de relações pessoais que avalia a sexualidade, houve redução da pontuação acima de 50\%, que foi significante entre os momentos pré e pós-operatório. Podemos inferir, pois, que houve melhora importante da qualidade de vida das mulheres operadas por esta técnica. 
Apesar da melhora clínica, a grande extensão do questionário, com mais de 50 perguntas somando todos os domínios, dificulta e prolonga o tempo de aplicação. Neste aspecto, estamos desenvolvendo um trabalho de validação no Brasil de um questionário de qualidade de vida sucinto e já validado na Inglaterra, com somente 21 questões e que poderá ser utilizado tanto em pacientes com prolapso quanto com incontinência urinária de esforço. ${ }^{56}$

Baseado em nossos resultados, futuros estudos devem ser realizados, comparando a técnica por nós utilizada com outras, como por exemplo, a fixação no ligamento sacroespinhal e a sacrofixação por via laparoscópica. 
6. Conclusão 
O tratamento cirúrgico do prolapso da cúpula vaginal pela técnica da sacropexia infra-coccígea permitiu-nos concluir que:

1. Foi efetivo e mostrou melhora clínica de 97,2\%;

2. Houve melhora significante da qualidade devida das mulheres estudadas. 
7. Anexos 
7.1 Anexo A 
Anexo A: Termo de consentimento livre e esclarecido

\section{TERMO DE CONSENTIMENTO LIVRE E ESCLARECIDO}

1. Nome:

Identidade: Data Nascimento: 1

Endereço:

Bairro: Cidade:

CEP: Telefones:

2. Responsável legal:

Natureza: Identidade:

Sexo: Data Nascimento:

Endereço:

Bairro: Cidade: CEP: Telefones:

\section{DADOS SOBRE A PESQUISA CIENTÍFICA}

1. Título da Pesquisa : "TRATAMENTO DO PROLAPSO DA CÚPULA VAGINAL PELA TÉCNICA DA SACROPEXIA INFRACOCCÍGEA"

2. Pesquisador: Lilian Corrêa Inscrição no Conselho Regional: 93901 Cargo: Médico colaborador Unidade do HCFMUSP: Disciplina de Ginecologia HCFMUSP

3. Risco da Pesquisa: Risco Médio

4. Duração da Pesquisa: aproximadamente 24 meses 


\section{TERMO DE CONSENTIMENTO LIVRE E ESCLARECIDO}

$\mathrm{Eu}$, estou sendo convidada e concordo em participar da

pesquisa: "Tratamento do prolapso da cúpula vaginal pela técnica da sacropexia infracoccígea“. O objetivo é utilizar uma faixa artificial, ou seja, feita de tecido não humano, para correção cirúrgica da bola que aparece na vagina.

Autorizo os médicos da equipe do Setor de Uroginecologia e Cirurgia Vaginal do Departamento de Ginecologia do Hospital das Clínicas a realizarem os exames pré-operatórios que forem necessários para o diagnóstico completo e tratamento da minha doença. Sei que vou ser submetida a uma cirurgia onde será colocada uma faixa artificial na parede da vagina para corrigir o meu problema.

Fui informada de que pode haver complicações da cirurgia como: sangramentos, infecção no local da cirurgia, furar o intestino, rejeição da faixa pelo meu corpo, com saída da faixa no local da cirurgia e até da cirurgia não resolver o meu problema.

Esta técnica está sendo utilizada no exterior com boa chance de cura do problema. Outros tipos de cirurgia para este problema existem, porém com grande chance de falha do tratamento. Esta pesquisa no Brasil será importante para orientar os médicos a fazer a melhor cirurgia para correção 
desta doença, e para avaliar as complicações que podem aparecer e orientar os médicos a evitá-las e resolvê-las.

Meu nome não aparecerá em momento algum na publicação desta pesquisa. Estou ciente que não terei que gastar dinheiro com o tratamento ou com os exames a serem realizados. Sei que posso me retirar da pesquisa a qualquer momento, e não terei meu atendimento no Hospital das Clínicas prejudicado, caso desista de participar.

Fui informada que tenho garantia de poder procurar os médicos do Hospital em qualquer situação relacionada a este projeto, dúvidas ou problemas com relação aos exames e a cirurgia.

Dra. Lilian Corrêa - 3061-9530

Dr. Ricardo Muniz Ribeiro - 5575-7197

\section{CONSENTIMENTO PÓS-ESCLARECIDO}

Declaro que, após convenientemente esclarecido pelo pesquisador e ter entendido o que me foi explicado, consinto em participar do presente Protocolo de Pesquisa.

Assinatura do sujeito da pesquisa ou responsável legal

Dra. Lilian Corrêa 
7.2 Anexo B 
Anexo B: Questionário de Qualidade de Vida em Prolapso - Versão II

\section{QUESTIONÁRIO DE QUALIDADE DE VIDA EM PROLAPSO - Versão II}

Prolapso é uma bola ou peso na vagina que causa incômodo

Nome:

Idade:

Data:

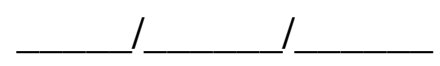

\section{PERCEPÇ̃̃O GERAL DE SAÚDE}

a. Como está sua saúde hoje?

1. Muito boa - (0)

2. Boa - (1)

3. Regular - (2)

4. Ruim - (3)

5. Muito Ruim - (4)

b. Como a bola ou peso na vagina atrapalha sua vida?

1. Não atrapalha em nada - (0)

2. Um pouco - (1)

3. Mais ou menos - (2)

4. Muito - (3)

c. Você vai muitas vezes ao banheiro para urinar?

1. Não - (0)

2. Um pouco - (1)

3. Mais ou menos (2)

4. Muito (3)

d. Você tem vontade forte de urinar e difícil de controlar?

1. Não - (0)

2. Um pouco - (1)

3. Mais ou menos (2)

4. Muito - (3)

e. Você perde urina quando tem muita vontade de urinar?

1. Não - (0)

2. Um pouco - (1)

3. Mais ou menos (2)

4. Muito - (3) 
f. Você sente que a bexiga não esvaziou depois de urinar?

1. Não - (0)

2. Um pouco $-(1)$

3. Mais ou menos (2)

4. Muito - (3)

g. Você sente uma bola ou peso dentro da vagina?

1. Não - (0)

2. Um pouco - (1)

3. Mais ou menos (2)

4. Bastante - (3)

h. Você tem a sensação de peso na vagina ou baixo ventre no decorrer do dia?

1. Não-(0)

2. Um pouco - (1)

3. Mais ou menos (2)

4. Bastante - (3)

i. Você tem dor na parte interna das coxas e na vagina?

1. Não - (0)

2. Um pouco $-(1)$

3. Mais ou menos (2)

4. Bastante - (3)

j. A bola ou peso atrapalha a sua evacuação?

1. Não - (0)

2. Um pouco - (1)

3. Mais ou menos (2)

4. Bastante - (3)

k. Você precisa usar os dedos para ajudar na evacuação?

1. Não - (0)

2. Um pouco - (1)

3. Mais ou menos (2)

4. Sempre - (3)

I. Para evacuar ajudando com as mãos você?

a) Empurra a bola para dentro da vagina:

1. Não - (0)

2. Às vezes $-(1)$

3. Várias vezes $-(2)$

4. Sempre - (3)

b) Utiliza os dedos para apertar entre a vagina e o ânus?

1. Não - (0)

2. Às vezes $-(1)$

3. Várias vezes $-(2)$

4. Sempre - (3) 
c) Coloca o dedo no ânus?
1. Não - (0)
2. Às vezes - (1)
3. Várias vezes - (2)
4. Sempre - (3)

m. Você tem dor nas costas que piora quando está em pé e melhora quando deita?

1. Não - (0)

2. Às vezes - (1)

3. Várias vezes - (2)

4. Sempre - (3)

n. O peso ou bola na vagina piora quando está em pé e melhora quando deita? (

1. Não - (0)

2. Às vezes - (1)

o. O seu jato de urina é fraco?

1. Normal - (0)

2. Um pouco fraco - (1)

3. Mais ou menos fraco - (2)

4. Bastante (3)

p. Você faz força para esvaziar a bexiga?

1. Não - (0)

2. Um pouco - (1)

3. Mais ou menos - (2)

4. Bastante - (3)

q. Você sente que continua pingando urina mesmo após ter urinado?

1. Não - (0)

2. Às vezes - (1)

3. Várias vezes - (2)

4. Sempre - (3)

r. Você sente que o intestino não esvaziou totalmente após a evacuação?

1. Não - (0)

2. Às vezes - (1)

3. Várias vezes - (2)

4. Sempre - (3)

S. Seu intestino é preso dificultando a evacuação?

1. Não - (0)

2. Um pouco $-(1)$

3. Mais ou menos - (2)

4. Muito - (3) 
t. Você faz força para evacuar? (

1. Não - (0)

2. Um pouco $-(1)$

3. Mais ou menos - (2)

4. Bastante - (3)

u. Você acha que a bola ou peso na vagina atrapalham a relação sexual? (

1. Não - (0)

2. Um pouco - (1)

3. Mais ou menos - (2)

4. Muito - (3)

v. Você acha que a bola na vagina piora a dor nas costas?

1. Não - (0)

2. Um pouco $-(1)$

3. Mais ou menos - (2)

4. Muito - (3)

w. Quantas vezes você evacua?

1. Uma vez ao dia - (0)

2. Mais de uma vez ao dia - (1)

3. A cada dois dias - (2)

4. A cada três dias - (3)

5. Uma vez por semana - (4)

\section{LIMITACÕES DE FUNCÃO}

a. Com que intensidade a sua bola ou peso na vagina atrapalham suas tarefas de casa? (limpar, lavar, cozinhar) - (

1. Não - (0)

2. Um pouco $-(1)$

3. Mais ou menos - (2)

4. Muito - (3)

b. Com que intensidade sua bola ou peso na vagina atrapalham seu trabalho e suas atividades diárias e normais fora de casa (compras, feira, mercado)?

1. Não-(0)

2. Um pouco - (1)

3. Mais ou menos - (2)

4. Muito - (3) 


\section{LIMITACÕ̃ES FÍSICAS E SOCIAIS}

a. Sua bola ou peso na vagina atrapalham suas atividades físicas como correr, andar ou fazer ginástica?

1. Não - (0)

2. Um pouco - (1)

3. Mais ou menos - (2)

4. Muito - (3)

b. Sua bola ou peso na vagina atrapalham quando você quer fazer uma viagem?

1. Não - (0)

2. Um pouco - (1)

3. Mais ou menos - (2)

4. Muito - (3)

c. Sua bola ou peso na vagina atrapalham quando você vai a igrejas, festas e reuniões?

1. Não - (0)

2. Um pouco - (1)

3. Mais ou menos - (2)

4. Muito - (3)

d. Você deixa de visitar seus amigos por causa da bola ou peso na vagina?

1. Não - (0)

2. Às vezes - (1)

3. Várias vezes - (2)

4. Sempre - (3)

\section{RELACIONAMENTOS PESSOAIS}

a. Seu peso ou bola na vagina atrapalham sua vida sexual?

1. Não se aplica - (0)

2. Não - (0)

3. Um pouco - (1)

4. Mais ou menos - (2)

5. Muito - (3)

b. Seu peso ou bola na vagina atrapalham seu dia a dia com seu parceiro?

1. Não se aplica - (0)

2. Não - (0)

3. Um pouco - (1)

4. Mais ou menos - (2)

5. Muito - (3) 
c. Seu peso ou bola na vagina incomodam seus familiares?

1. Não se aplica - (0)

2. Não-(0)

3. Um pouco $-(1)$

4. Mais ou menos - (2)

5. Muito - (3)

5. EMOCÕES

a. Você fica deprimida com seu peso ou bola na vagina?

1. Não - (0)

2. Um pouco - (1)

3. Mais ou menos $-(2)$

4. Muito - (3)

b. Você fica ansiosa ou nervosa com seu peso na vagina?

1. Não - (0)

2. Um pouco $-(1)$

3. Mais ou menos - (2)

4. Muito - (3)

c. Você fica mal com você mesma devido ao se peso ou bola na vagina?

1. Não - (0)

2. Um pouco $-(1)$

3. Mais ou menos $-(2)$

4. Muito - (3)

6. SONO E ENERGIA

a. A sua bola ou peso na vagina atrapalham seu sono:

1. Não - (0)

2. Às vezes $-(1)$

3. Várias vezes - (2)

4. Sempre - (3)

b. Você se sente cansada, esgotada e exausta?

1. Não - (0)

2. Às vezes - (1)

3. Várias vezes - (2)

4. Sempre - (3) 
c. Você usa tampão absorvente ou calçinha apertada para segurar a bola na vagina?

1. Não - (0)

2. Às vezes - (1)

3. Várias vezes - (2)

4. Sempre - (3)

d. Você empurra a bola para dentro da vagina?

1. Não - (0)

2. Às vezes - (1)

3. Várias vezes - (2)

4. Sempre - (3)

e. Você sente dor ou incômodo com a bola ou peso na vagina?

1. Não - (0)

2. Às vezes - (1)

3. Várias vezes - (2)

4. Sempre - (3)

f. A bola ou peso na vagina te impedem de ficar em pé?

1. Não - (0)

2. Às vezes $-(1)$

3. Várias vezes - (2)

4. Sempre - (3)

Pontuação total 
7.3 Anexo C 
Anexo C: Evolução do Ponto Ba na casuística estudada.

\begin{tabular}{|c|c|c|c|c|c|c|c|c|c|c|}
\hline \multirow[t]{3}{*}{ CASOS } & \multirow{3}{*}{$\begin{array}{c}\text { Tempo } \\
\text { (meses) }\end{array}$} & \multirow{3}{*}{$\begin{array}{c}\text { Pré- } \\
\text { operatório }\end{array}$} & \multicolumn{8}{|c|}{ PONTO Ba } \\
\hline & & & \multicolumn{8}{|c|}{$\begin{array}{c}\text { Pós-operatório } \\
\text { (meses) }\end{array}$} \\
\hline & & & 1 & 3 & 6 & 12 & 24 & 36 & 48 & 60 \\
\hline ACS & 30 & -2 & -3 & -3 & -3 & -3 & -3 & -3 & -3 & -3 \\
\hline CMS & 53 & +2 & -3 & -3 & -3 & -3 & -3 & -3 & -3 & -3 \\
\hline DF & 15 & -1 & -3 & -3 & +3 & $-3^{1}$ & - & - & - & - \\
\hline ERS & 40 & +6 & -3 & -3 & -3 & -3 & -3 & -3 & -3 & - \\
\hline ER & 28 & +8 & -3 & -3 & -3 & -3 & -3 & - & - & - \\
\hline ETZ & 32 & +5 & -3 & -3 & -3 & -3 & -3 & - & - & - \\
\hline FAZ & 39 & +7 & -3 & -3 & -3 & -3 & -3 & -3 & -3 & - \\
\hline HLW & 39 & +6 & -3 & -3 & -2 & +1 & $-3^{1}$ & -3 & -3 & - \\
\hline IB & 46 & +6 & -3 & -3 & -1 & -1 & -1 & -1 & -1 & - \\
\hline JDMC & 18 & +3 & -3 & -3 & -3 & -3 & - & - & - & - \\
\hline JMS & 44 & +5 & -3 & -3 & -3 & -3 & -3 & -3 & -3 & - \\
\hline LAFS & 21 & +4 & -3 & -3 & -3 & -3 & - & - & - & - \\
\hline LGM & 55 & +6 & -3 & -3 & -3 & -3 & -3 & -3 & -3 & -3 \\
\hline LHI & 19 & +5 & -3 & -3 & -3 & -3 & - & - & - & - \\
\hline LAL & 12 & +6 & -3 & -2 & -2 & -2 & - & - & - & - \\
\hline MAC & 13 & -3 & -3 & -3 & -3 & -3 & - & - & - & - \\
\hline MDBR & 10 & +9 & -3 & -3 & -3 & -3 & - & - & - & - \\
\hline MSS & 42 & +2 & -3 & -3 & -3 & -3 & -2 & -2 & -2 & - \\
\hline MECAC & 19 & +7 & -3 & -3 & -1 & -1 & - & - & - & - \\
\hline MJO & 44 & +7 & -3 & -3 & -3 & -3 & -2 & -3 & -3 & - \\
\hline MFP & 47 & +6 & -3 & -3 & -3 & -3 & -3 & -3 & -3 & - \\
\hline MISG & 17 & +5 & -3 & -3 & -3 & -3 & - & - & - & - \\
\hline MLS & 13 & +7 & -3 & -3 & -3 & -3 & - & - & - & - \\
\hline MNA & 52 & 0 & -3 & -3 & -3 & -3 & -3 & -3 & -3 & -3 \\
\hline MRS & 35 & +3 & -3 & -3 & -2 & 0 & 0 & - & - & - \\
\hline MZPD & 20 & +8 & -3 & -3 & -2 & -1 & - & - & - & - \\
\hline NRM & 18 & +7 & -3 & -3 & -3 & -3 & - & - & - & - \\
\hline $\mathrm{NC}$ & 33 & +6 & -3 & -3 & -1 & +2 & +2 & - & - & - \\
\hline PMA & 22 & +8 & -3 & -3 & -3 & -3 & - & - & - & - \\
\hline OMCV & 40 & +7 & -3 & -3 & -3 & -3 & -3 & -3 & -3 & - \\
\hline RSS & 17 & +7 & -3 & -3 & -1 & 0 & - & - & - & - \\
\hline SMS & 45 & +6 & -3 & -3 & -3 & -3 & -3 & -3 & -3 & - \\
\hline SER & 39 & +10 & -3 & -3 & -3 & -3 & -3 & -3 & -3 & - \\
\hline TPS & 33 & +3 & -3 & -3 & -2 & -2 & -2 & - & - & - \\
\hline TJC & 31 & +3 & -3 & -3 & -2 & +3 & +3 & - & - & - \\
\hline VFP & 31 & +7 & -3 & -3 & -3 & -3 & -3 & - & - & - \\
\hline
\end{tabular}


7.4 Anexo D 
Anexo D: Evolução do Ponto Bp na casuística estudada

\begin{tabular}{|c|c|c|c|c|c|c|c|c|c|c|}
\hline \multirow[t]{3}{*}{ CASOS } & \multirow{3}{*}{$\begin{array}{c}\text { Tempo } \\
\text { (meses) }\end{array}$} & \multirow{3}{*}{$\begin{array}{c}\text { Pré- } \\
\text {-operatório }\end{array}$} & \multirow{2}{*}{\multicolumn{7}{|c|}{$\begin{array}{c}\text { PONTO Bp } \\
\text { Pós-operatório } \\
\text { (meses) }\end{array}$}} & \multirow[b]{3}{*}{60} \\
\hline & & & & & & & & & & \\
\hline & & & 1 & 3 & 6 & 12 & 24 & 36 & 48 & \\
\hline ACS & 30 & +6 & -3 & -3 & -3 & -3 & -3 & -3 & -3 & -3 \\
\hline CMS & 53 & +6 & -3 & -3 & -3 & -3 & -3 & -3 & -3 & -3 \\
\hline DF & 15 & +6 & -3 & -3 & -3 & -3 & - & - & - & - \\
\hline ERS & 40 & +6 & -3 & -3 & -3 & -3 & -3 & -3 & -3 & - \\
\hline ER & 28 & +7 & -3 & -3 & -3 & -3 & -3 & - & - & - \\
\hline ETZ & 32 & +7 & -3 & -3 & -3 & -3 & -3 & - & - & - \\
\hline FAZ & 39 & +7 & -3 & -3 & -3 & -3 & -3 & -3 & -3 & - \\
\hline HLW & 39 & +6 & -3 & -3 & -3 & -3 & -3 & -3 & -3 & - \\
\hline IB & 46 & +6 & -3 & -3 & -3 & -3 & -3 & -3 & -3 & - \\
\hline JDMC & 18 & +6 & -3 & -3 & -3 & -3 & - & - & - & - \\
\hline JMS & 44 & +5 & -3 & -3 & -3 & -3 & -3 & -3 & -3 & - \\
\hline LAFS & 21 & +4 & -3 & -3 & -3 & -3 & - & - & - & - \\
\hline LGM & 55 & +6 & -3 & -3 & -3 & -3 & -3 & -3 & -3 & -3 \\
\hline LHI & 19 & +6 & -3 & -3 & -3 & -3 & - & - & - & - \\
\hline LAL & 12 & +7 & -3 & -3 & -3 & -3 & - & - & - & - \\
\hline MAC & 13 & +7 & -3 & -3 & -3 & -3 & - & - & - & - \\
\hline MDBR & 10 & +9 & -3 & -3 & -3 & -3 & - & - & - & - \\
\hline MSS & 42 & +3 & -3 & -3 & -3 & -3 & -3 & -3 & -3 & - \\
\hline MECAC & 19 & +7 & -3 & -3 & -3 & -3 & - & - & - & - \\
\hline MJO & 44 & +7 & -2 & -2 & -2 & -2 & -2 & -2 & -2 & - \\
\hline MFP & 47 & +6 & -3 & -3 & -3 & -3 & -3 & -3 & -3 & - \\
\hline MISG & 17 & +3 & -3 & -3 & -3 & -3 & - & - & - & - \\
\hline MLS & 13 & +5 & -3 & -3 & -3 & -3 & - & - & - & - \\
\hline MNA & 52 & +3 & -2 & -2 & -2 & -2 & -2 & -2 & -2 & -2 \\
\hline MRS & 35 & +2 & -3 & -3 & -3 & -3 & -3 & - & - & - \\
\hline MZPD & 20 & +3 & -3 & -3 & -3 & -3 & - & - & - & - \\
\hline NRM & 18 & +5 & -3 & -3 & -3 & -3 & - & - & - & - \\
\hline NC & 33 & +6 & -3 & -3 & -3 & -3 & -3 & - & - & - \\
\hline PMA & 22 & +8 & -3 & -3 & -3 & -3 & - & - & - & - \\
\hline OMCV & 40 & +7 & -3 & -3 & -3 & -3 & -3 & -3 & -3 & - \\
\hline RSS & 17 & +7 & -3 & -3 & -2 & -2 & - & - & - & - \\
\hline SMS & 45 & +6 & -3 & -3 & -3 & -3 & -3 & -3 & -3 & - \\
\hline SER & 39 & +10 & -3 & -3 & -3 & -3 & -3 & -3 & -3 & - \\
\hline TPS & 33 & +2 & -3 & -3 & -3 & -3 & -3 & - & - & - \\
\hline TJC & 31 & +7 & -3 & -3 & -3 & -3 & -3 & - & - & - \\
\hline VFP & 31 & +7 & -3 & -3 & -3 & -3 & -3 & - & - & - \\
\hline
\end{tabular}


7.5 Anexo E 
Anexo E: Evolução do Ponto C na casuística estudada.

\begin{tabular}{|c|c|c|c|c|c|c|c|c|c|c|}
\hline \multirow[t]{3}{*}{ CASOS } & \multirow{3}{*}{$\begin{array}{c}\text { Tempo } \\
\text { (meses) }\end{array}$} & \multirow{3}{*}{$\begin{array}{c}\text { Pré- } \\
\text { operatório }\end{array}$} & \multicolumn{8}{|c|}{ PONTO C } \\
\hline & & & \multicolumn{8}{|c|}{$\begin{array}{l}\text { Pós-operatório } \\
\text { (meses) }\end{array}$} \\
\hline & & & 1 & 3 & 6 & 12 & 24 & 36 & 48 & 60 \\
\hline ACS & 30 & +5 & -6 & -6 & -6 & -6 & -6 & -6 & -6 & -6 \\
\hline CMS & 53 & +6 & -6 & -6 & -6 & -6 & -6 & -6 & -6 & -6 \\
\hline DF & 15 & +5 & -8 & -8 & -7 & -7 & - & - & - & - \\
\hline ERS & 40 & +6 & -6 & -6 & -6 & -6 & -6 & -6 & -6 & - \\
\hline ER & 28 & +7 & -8 & -8 & -8 & -8 & -8 & - & - & - \\
\hline ETZ & 32 & +5 & -8 & -8 & -8 & -8 & -8 & - & - & - \\
\hline FAZ & 39 & +7 & -7 & -7 & -7 & -7 & -7 & -7 & -7 & - \\
\hline HLW & 39 & +6 & -7 & -7 & -7 & -7 & -7 & -7 & -7 & - \\
\hline IB & 46 & +6 & -6 & -6 & -6 & -6 & -6 & -6 & -6 & - \\
\hline JDMC & 18 & +3 & -8 & -8 & -8 & -8 & - & - & - & - \\
\hline JMS & 44 & +5 & -6 & -6 & -6 & -6 & -6 & -6 & -6 & - \\
\hline LAFS & 21 & +4 & -6 & -6 & -6 & -6 & - & - & - & - \\
\hline LGM & 55 & +6 & -6 & -6 & -6 & -6 & -6 & -6 & -6 & -6 \\
\hline LHI & 19 & +5 & -8 & -8 & -8 & -8 & - & - & - & - \\
\hline LAL & 12 & +7 & -6 & -6 & -6 & -6 & - & - & - & - \\
\hline MAC & 13 & +6 & -9 & -9 & -9 & -9 & - & - & - & - \\
\hline MDBR & 10 & +9 & -8 & -8 & -8 & -8 & - & - & - & - \\
\hline MSS & 42 & +7 & -8 & -8 & -8 & -8 & -8 & -8 & -8 & - \\
\hline MECAC & 19 & +7 & -5 & -5 & -5 & -5 & - & - & - & - \\
\hline MJO & 44 & +7 & -6 & -6 & -6 & -6 & -2 & 0 & +3 & - \\
\hline MFP & 47 & +6 & -8 & -8 & -8 & -8 & -8 & -8 & -8 & - \\
\hline MISG & 17 & +3 & -9 & -9 & -9 & -9 & - & - & - & - \\
\hline MLS & 13 & +5 & -5 & -5 & -5 & -5 & - & - & - & - \\
\hline MNA & 52 & +7 & -6 & -6 & -6 & -6 & -5 & -5 & -5 & -5 \\
\hline MRS & 35 & +2 & -7 & -7 & -7 & -7 & -7 & - & - & - \\
\hline MZPD & 20 & +8 & -7 & -7 & -7 & -7 & - & - & - & - \\
\hline NRM & 18 & +5 & -7 & -7 & -7 & -7 & - & - & - & - \\
\hline $\mathrm{NC}$ & 33 & +6 & -6 & -6 & -6 & -6 & -6 & - & - & - \\
\hline PMA & 22 & +8 & -10 & -10 & -10 & -10 & - & - & - & - \\
\hline OMCV & 40 & +7 & -7 & -7 & -7 & -7 & -7 & -7 & -7 & - \\
\hline RSS & 17 & +7 & -5 & -5 & -5 & -5 & - & - & - & - \\
\hline SMS & 45 & +6 & -5 & -5 & -5 & -5 & -5 & -5 & -5 & - \\
\hline SER & 39 & +10 & -6 & -6 & -6 & -6 & -6 & -6 & -6 & - \\
\hline TPS & 33 & +2 & -8 & -8 & -8 & -8 & -8 & - & - & - \\
\hline $\mathrm{TJC}$ & 31 & +6 & -6 & -6 & -5 & -4 & -4 & - & - & - \\
\hline VFP & 31 & +7 & -6 & -6 & -6 & -6 & -6 & - & - & - \\
\hline
\end{tabular}


8. Referências 
1. Mant J, Painter R, Vessey M. Epidemiology of genital prolapsed: observations from Oxford Family Planning Association Study. $\mathrm{Br} \mathrm{J}$ Obstet Gynaecol. 1997;104:579-85.

2. Marchionni M, Bracco GL, Checcucci V, Carabaneanu A, Coccia EM, Mecacci $\mathrm{F}$ et al. True incidence of vaginal vault prolapsed. Thirteen years of experience. J Reprod Med. 1999;44:679-85.

3. Dallenbach P, Kaelin-Gambirasio I, Dubuisson JB, Boulvain M. Risk factors for pelvic organ prolapsed repair after hysterectomy. Obstet Gynecol. 2007;110:625-32.

4. Dallenbach P, Kaelin-Gambirasio, Jacob S, Dubuisson JB. Incidence rate and risk factors for vaginal vault prolapsed repair after hysterectomy. Int Urogynecol J. 2008;19:1623-9.

5. Pilsgaard K, Mouritsen L. Follow-up after repair of vaginal vault prolapsed with abdominal colposacropexy. Acta Obstet Gynecol Scand. 1999;78:66-70.

6. Bump RC. Racial comparisons and contrasts in urinary incontinence and pelvic organ prolapsed. Obstet Gynecol. 1993;81 421-5.

7. Graham CA, Mallet VT. Race as predictor of urinary incontinence and pelvic organ prolapsed. Am J Obstet Gynecol. 2001;185:116-20.

8. Nichols DH. Vaginal surgery. Williams \& Wilkins, Batimore, 1978.

9. Fothergill, WE. Pathology and the operative treatment of displacements of the pelvic víscera. J Obstet Gynaecol Br Emp. $1907 ; 13: 410-9$. 
10. Paramore, $\mathrm{RH}$. The supports in chief of the female pelvic viscera. $J$ Obstet Gynaecol Br Emp 1908;30:391-409.

11.De Lancey JOL. Anatomic aspects of vaginal evertion after hysterectomy. Am J Obstet Gynecol. 1992;166:1717-28.

12. Petros PEP. Vault prolapsed I: Dynamics supports of the vagina. Int Urogynecol J. 2001;12:292-5.

13. Bump RC, Mattiasson A, Bo K, Brubaker LP, DeLancey JOL, Klarskov $\mathrm{P}$, Shull BL, Smith ARB. The standardization of terminology of female pelvic organ prolapse and pelvic floor dysfunction. Am J Obstet Gyneco. 1996;175:10-7.

14. Digesu AG, Khullar V, Cardozo L, Robinson D, Salvatore S. P-QOL: a validated questionnaire to assess the symptoms and quality of life of women with urogenital prolapse. Int Urogynecol J. 2005;16:176-81.

15. Digesu GA, Santamato S, Khullar V, Santillo V, Digesu A, Cormio G, Loverro G, Selvaggi L. Validation of na Italian version os the prolapse quality of life questionnaire. Eur J Obstet Gynecol. 2003;106:184-92.

16. Langmade CF, Oliver JA Jr, White JS. Cooper ligament repair of vaginal vault prolapsed twenty-eight years later. Am J Obstet Gynecol. $1978 ; 15 ; 131: 134-42$.

17. Lane, FE. Repair of posthysterectomy vaginal vault prolapsed. Obstet Gynecol. 1962;20:72-6.

18. Vries MJ, Van Dessel THJM, Drogendijik AC, Haas I, Huikeshoven FJM. Short term results and long-term patients appraisal of abdominal colposacropexy for treatment of genital and vaginal vault prolapsed. Eur J Obstet Gynecol. 1995;59:35-8. 
19. Timmons MC, Addison WA, Addison SB, Cavenar MG. Abdominal sacral colpopexy in 163 women with posthysterectomy vaginal vault prolapsed and enterocele. Evolution of operative techniques. J Reprod Med. 1992;37:323-7.

20. Beer M, Kuhn A. Surgical techniques for vault prolapsed: a review of the literature. J Obstet Reprod Biol. 2005;119;144-55.

21. Kohli N, Walsh PM, Roat TW, Karram MM. Mesh erosion after abdominal sacrocolpopexy. Obstet Gynecol. 1998;92:999-1004.

22. Mattox TF, Stanford EJ, Varner E. infected abdominal sacrocolpopexies: diagnosis and treatment. Int Urogynecol $\mathrm{J}$. 2004;15:319-23.

23. Drutz HP, Cha LS. Massive genital and vaginal vault prolapsed treated by abdominal-vaginal sacropexy with use of Marlex mesh: review of literature. Am J Obstet Gynecol. 1987;156:387-92.

24. Visco AG, Weidner AC, Barber MD, Myers ER, Cundiff GW, Bump RC, Addison WA. Vaginal mesh erosion after abdominal sacral colpopexy. Am J Obstet Gynecol. 2001;184:297-302.

25. Culligan PJ, Murphy M, Blackwell L, Hammons G, Graham C, Heit M. Long-term success of abdominal sacral colpopexy using synthetic mesh. Am J Obstet Gynecol. 2002;187:1473-8.

26. Bensinger G, Llind L, Lesser M, Guess M, Winkler HA. Abdominal sacral suspensions: analysis of complications using permanent mesh. Am J Obstet Gynecol. 2005;Dec;193:2094-8. 
27. Brizzolara S, Pillai-Allen A. Risk of mesh erosion with sacral colpopexy and concurrent hysterectomy. Obstet Gynecol. 2003;102:306-10.

28. Marinkovic SP. Will hysterectomy at the time of sacrocolpopexy increase the rate of polypropylene mesh erosion? Int Urogynecol J Penvic Floor Dysfunct. 2008;Feb;19:199-203.

29. Lucioni A,Rapp DE, Gong EM, Reynolds WS, Fedunok PA, Bales GT. The surgical technique and early postoperative complications of the Gynecare Prolift Pelvic Floor Repair System. Can J Urol. 2008;15:4004-8.

30. Stepanian AA, Miklos JR, Moore RD, Mattox TF. Risk of mesh extrusion and other mesh-related complications after laparoscopic sacral colpopexy with or without concurrent laparoscopic-assisted vaginal hysterectomy: experience of 402 patients. J Minim Invasive Gynecol. 2008;15;188-96.

31. Lee HJ, Lee Ys, Koo TB, Cho YI, Park IS. Laparoscopic management of uterine prolapsed with cystocele and rectocele using "Gynemesh PS". J Laparoendosc Adv Surg Tech A. 2008;18:93-8.

32. Clavero PA, Guerrero JA, Salamanca A. Gore-Tex mesh pelvic occlusion and secondary colpopexy: A new surgical technique for posthysterectomy vaginal vault prolapse. Eur J Obstet Gynecol. 2006;126:113-5.

33. Ross JW. The use of a xenogenic barrier to prevent mesh erosion with laparoscopic sacrocolpopexy. J Minim Invasive Gynecol. $2007 ; 14 ; 470-4$. 
34. Govier Fe, Kobashi KC, Kozlowski PM, Kuznetsov DD, Begley SJ, McGonigle KF, Muntz HG. High complication rate identified in sacrocolpopexy patients attributed to silicone mesh. Urology. 2005;65;1099-103.

35. Amreich IA. Aetiologie und operation des scheidenstumpfprolapses. Wien Klin Wochenschr. 1951;63:74-7.

36. Richter K. Die Chirurgische anatomie des vaginaefixation sacrospinalis: Ein beitrag zur operative behandlung des scheidenblindsackprolapses. Geburth Frauenheilk. 1968;28:321-7.

37. Cruikshank SH, Muniz M. Outcomes study: A comparison of cure rates in 695 patients undergoing sacrospinous ligament fixation alone and with other site-specific procedures - a 16 year study. Am J Obstet Gynecol. 2003;188;1509-15.

38. Paraiso MF, Ballard LA, Wallace MD. Pelvic support defects and visceral and sexual function in women treated with sacrospinous ligament suspension and pelvic reconstruction. Am J Obstet Gynecol. 1996;175:1423-31.

39. Holley RJ, Varner RE, Gleason BP. Recurrent pelvic support defects after sacrospinous ligament fixation for vaginal vault prolapsed. J Am Coll Surg. 1995;180:444-8.

40. Lo TS, Horing SG, Huang HJ, Lee SJ, Liang CC. Repair of recurrent vaginal vault prolapsed using sacrospinous ligament fixation with mesh interposition and reinforcement. Acta Obstet Gynecol Scand. 2005;84:992-5. 
41. Lovatsis D, Drutz HP. Safety and efficacy of sacrospinous vault suspension. Int Urogynecol J Pelvic Floor Dysfunc. 2002;13:308-13.

42. Petros PE, Ulmsten UI. An integral theory of female urinary incontinence. Experimental and clinical considerations. Acta Obstet Gynecol Scand. Suppl 1990;153:7-31.

43. Petros PE. Development of generic models for ambulatory vaginal surgery - a preliminary repost. Int. Urogynecol. 1998;9:19-27.

44. Petros PE. The intravaginal slingplasty operation, a minimally invasive technique for cure of urinary incontinence in the female. Aust $N Z$ Obstet Gynecol. 1996;36:453-61.

45. Petros PE. New ambulatory surgical methods using an anatomical clsssification of urinary dysfunction improve stress, urge and abnormal emptying. Int Gynecol J. 1997;8:270-8.

46. Petros PE. Vault prolapsed II: restoration of dynamic vaginal supports by infracoccigeal sacropexy, an axial day-case vaginal procedure. Int Urogynecol J. 2001;12:296-303.

47. Farsworth BN. Posterior intravaginal slingplasty (infracoccygeal sacropexy) for severe posthysterectomy vaginal vault prolapse - a preliminary report on efficacy and safety. Int Urogynecol. 2002;13:4-8.

48. Deffieux X, Desseaux K, Tayrac R, Faivre E, Frydman R, Fernandez H. Infracoccygeal sacropexy for uterovaginal prolapse. Int J Gynaecol Obstet. 2009;104:56-9.

49. Foote AJ, Ralph J. Infracoccygeal sacropexy. Austr N Z Obstet Gynecol. 2007;47:250-1. 
50. Sivaslioglu AA, Gelisen O, Dolen I, Dede H, Dilbaz S, Haberal A. Posterior sling (infracoccygeal sacropexy): na alternative procedure for vaginal vault prolapse. Aust N Z Obstet Gynecol. 2005;45:159-60.

51. Ghanbari A, Bratali BH, Mireshghi MS. Posterior intravaginal slingplasty (infracoccygeal sacropexy) in the treatment of vaginal vault prolapse. Int J Gynecol Obstet. 2006;94:147-8.

52. Sentilhes L, Sergent F, Reschnfracoccygeal sacropexy reinforced with posterior mesh interposition for apical and posterior compartment prolapsed. Eur J Obstet Gynecol. 2008;137:108-13.

53. Kim M, Kim JH, Cho HH. Infracoccygeal sacropexy improves the quality of life of women with uterine prolapsed. Maturitas. 2008;59:158-62

54. Tayrac R, Mathé ML, Bader G, Deffieux X, Fazel A, Fernandez H. Infracoccygeal sacropexy or sacrospinous suspension for uterine or vaginal vault prolapse. Int J Gynecol Obstet. 2008;100:154-9.

55. Jelonsek JE, Sokol AL, Barber MD, Paraiso MFR, Walters MD. Anatomic relationships of infracoccygeal sacropexy (posterior intravaginal slingplasty) trocar insertion. $A m \mathrm{~J}$ Obstet Gynecol. 2005;193:2099-104.

56. Barber MD, Walters MD, Bump RC. Short forms of two condition-specific quality-of-life questionnaires for women with pelvic floor disorders (PFDI-20 and PFIQ-7). Am J Obstet Gynecol. 2005;193:103-13. 